\title{
COPYRIGHT AND JOINT AUTHORSHIP AS A DISRUPTION OF THE VIDEO GAME STREAMING INDUSTRY
}

\author{
John Holden* and Mike Schuster**
}

Video game streaming on sites like YouTube and Twitch is now a billion-dollar industry. Top streaming personalities make tens of millions of dollars annually, as viewership of video game play continues to expand. While video game companies' control over intellectual property embodied in video games is largely accepted, streamers' rights in their recorded gameplay have yet to be settled.

Game companies likely maintain the right to stop unauthorized streaming of gameplay, but most do not exercise that right, as streaming represents free advertising. This raises the related question of what rights streamers have against unauthorized use of their gameplay. It also raises the question, unexplored in the literature, of what rights gameplayers maintain when competitors in their online games stream their matches.

We find that copyright can provide protection to streamers over the audiovisual recordings of their play, subject to contractual limitations imposed by game companies. Our analysis likewise establishes that gamers whose play is streamed by another party may qualify as joint authors of the streamed recording. This co-authorship could result in multimillionaire streamers owing an accounting to other players appearing in their streams. The Article then explores the potential business implications associated with these findings and discusses potential strategies to protect the interests of game companies and streamers.

* Assistant Professor at the Oklahoma State University Spears School of Business. Authors listed in random order.

** Assistant Professor at the University of Georgia Terry College of Business; Courtesy Appointment at the University of Georgia School of Law. 
I. Introduction ..................................................... 944

II. An Overview of the Esports Environment ................947

A. A Brief Overview of Streaming ..........................952

B. The EULA and Contracts...................................957

III. Copyright and Video Games .......................................963

A. Derivative Works in Gameplay ..........................965

B. Creativity .......................................................966

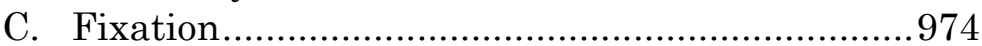

IV. Joint Authorship ...................................................981

A. Game Company/Player Joint Authorship ...........983

B. Player/Player Joint Authorship ........................984

1. Recording in Server ...................................986

2. Local Recording by the Video Game ..............987

3. Local Recording Outside the Video Game .....989

V. Implications and Strategic Responses.......................991

A. Preventing Copying of Streams .........................991

B. Accounting to Other Gamers...............................993

C. Considerations for Game Companies..................996

VI. Conclusion..................................................................997 


\section{INTRODUCTION}

Streaming1 is now ubiquitous. ${ }^{2}$ Netflix has 60.6 million subscribers in the United States, and nearly 100 million internationally. 3 Of course, Netflix is not alone. 4 In 2019, more than half the population of the United States viewed content via a streaming service. 5 While many people think of Netflix, Amazon Prime, or Hulu when they hear the word streaming, websites such as Twitch, YouTube, Facebook, and Microsoft's now-defunct Mixer have dominated video game

1 Streaming refers to listening to or watching content "in 'real time,' instead of downloading a file to your computer and" listening to or watching it. What Is Streaming?, BBC: WeBWIsE (Oct. 10, 2012), http://www.bbc.co.uk/webwise/guides/about-streaming

[https://perma.cc/9JGL-UQQ2]. Streaming is a technology that relies on high-speed internet connections in order to deliver the content without interruptions. Id. Platforms like Twitch and YouTube allow individuals to live stream their video game play to viewers around the world. See Devon Delfino, 'What is Twitch?': Here's What You Need to Know About the World's Leading Live-Streaming Platform for Gamers, Bus. INSIDER (June 11, 2020, 11:58 AM),

https://www.businessinsider.com/what-is-

twitch\#: :text=Twitch\%20is\%20a\%20live\%2Dstreaming,hear\%20and $\% 20$

watch\%20them\%20live [https://perma.cc/HYA5-7NQ5] (discussing Twitch). These video game streaming sites allow a streamer to share their screen and broadcast it users. $I d$. In addition to live streaming, users can stream archived material. Id.

2 The streaming website Twitch averaged 2.39 million concurrent viewers in October 2020. See Twitch Statistics \& Charts, TwITCHTRACKER fig.Concurrent Viewers (last visited Nov. 4, 2020), https://twitchtracker.com/statistics [https://perma.cc/UK82-HJCH].

3 Joe Flint \& Micah Maidenberg, Netflix Subscribers Fall Slightly Short of Expectations, WALL ST. J. (Oct. 16, 2019), https://www.wsj.com/articles/netflix-subscribers-fall-slightly-short-ofexpectations-11571257175 (on file with the Columbia Business Law Review).

4 See Dana Feldman, Netflix's Dominance in U.S. Wanes as Hulu, Amazon Gain Subscribers, ForBes (Aug. 21, 2019, 1:10 PM),

https://www.forbes.com/sites/danafeldman/2019/08/21/netflix-is-expectedto-lose-us-share-as-rivals-gain/\#1a473e166d67

[https://perma.cc/E98F-59GB].

5 See id. (projecting the viewing fraction of the population that year to be $55.3 \%)$. 
streaming. 6 Of these platforms, Twitch accounts for seventytwo percent of the live-streaming market, which in the second quarter of 2019 equaled nearly 2.75 billion hours of content. 7 Viewers on Twitch and other streaming platforms are not, however, watching reruns of Friends or Breaking Bad, as they may on Netflix. They are primarily watching other people play video games. 8 Despite jokes from late night comedians about streaming, 9 the reality is that Twitch and YouTube are growing at rates of which traditional sports leagues can only dream.10 From a business perspective, however the billiondollar video game streaming industry exists on a somewhat shaky foundation and largely at the pleasure of game makers. The industry, which has produced riches for a select few celebrity streamers, may also have been built without consideration of extant copyright claims, notably, in some instances, claims to joint authorship. 11

Streaming video game content presents a unique context in which to examine the application of old concepts to new technology. ${ }^{12}$ Some have compared video game streaming to

6 See Sarah Perez, Twitch Continues To Dominate Live Streaming with Its Second-Biggest Quarter To Date, TECHCRUNCH (July 12, 2019, 3:14 PM), https://techcrunch.com/2019/07/12/twitch-continues-to-dominate-livestreaming-with-its-second-biggest-quarter-to-date/ [https://perma.cc/CA7AHD35].

$7 \mathrm{Id}$.

8 See id.

9 Comedian Jimmy Kimmel famously mocked streamers and esports on his late night program and the clip quickly received thousands of "dislikes" on YouTube. See Paul Tassi, Jimmy Kimmel Made Fun of Streaming and Proved Gamers Can't Take a Joke, Forbes (Sept. 2, 2015, 12:25 AM), https://www.forbes.com/sites/insertcoin/2015/09/02/jimmy-kimmel-madefun-of-streaming-and-proved-gamers-cant-take-a-joke/\#10a39f2e3483 [https://perma.cc/N74C-JZ35].

10 See generally Christopher D. Merwin et AL., Goldman Sachs, The World of Games: eSports: From Wild West to Mainstream (2018), https://www.goldmansachs.com/insights/pages/infographics/esports/report.pdf [https://perma.cc/W8PD-F92F].

11 See infra Part IV.

12 Cf. Alex Hern, Video Game Streaming: Is It Worth It?, GUARDIAN (July 26, 2019, 8:00 AM), 
sports broadcasts and analyzed the applicability of copyright protection. 13 This, however, is the first paper to examine the potential for gamers within the multibillion-dollar streaming industry to be joint authors of their gameplay.

These joint authorship issues arise in front of millions of viewers every day on websites like Twitch and YouTube.14 Video game players compete online while one of themperhaps a celebrity streamer-broadcasts the action via live stream. 15 There is a strong argument that the audiovisual stream of the gameplay (distinct from the game's underlying software code) is a copyrightable joint work, such that cocreators may be compensated out of the streamer's earnings. 16 Adopting this view necessitates a significant reevaluation of the industry for streamers and video game companies. Unlike athletes in traditional sports, competitive video gamers create copyrighted joint works during their play, making theirs a distinct segment of the entertainment industry. 17

https://www.theguardian.com/games/2019/jul/26/video-game-streaming-isit-worth-it [https://perma.cc/S39A-RYSJ] (discussing ways in which streaming alters existing technologies).

13 See Madeleine A. Ball, Note, Nerf This: Copyright Highly Creative Video Game Streams as Sports Broadcasts, 61 WM. \& MARY L. REV. 253, 284 (2019) (arguing that there is ample precedent to support courts protecting streamers' copyright claims).

14 See supra notes 6-7 and accompanying text.

15 See Kevin Webb, The 10 Most Popular Channels on Twitch, Bus. INSIDER (Oct. 2, 2019, 11:02 AM), https://www.businessinsider.com/toptwitch-streamers-by-follower-count-ninja-shroud-tfue-2019-6 [https://perma.cc/WGE3-EBXZ].

16 See infra Section IV.B. Some top streamers bring in more than $\$ 20,000$ per month. See James Hale, Here's a Candid Breakdown of Exactly How Much Money Twitch Streamers Earn Per Month, TubefILTER (Oct. 10, 2018), https://www.tubefilter.com/2018/10/10/twitch-streamers-earn-permonth-breakdown-disguisedtoast/ [https://perma.cc/SQN7-VY5R].

17 The game play of basketball, unlike its broadcast and unlike the play of video games, is incapable of copyright protection. See Nat'l Basketball Ass'n v. Motorola, Inc., 105 F.3d 841, 846-47 (2d Cir. 1997) (holding that athletic events are not "authored" and therefore not within the scope of copyright protection); Atari, Inc. v. N. Am. Philips Consumer Elecs. Corp., 672 F.2d 607, 619-620 (7th Cir. 1982) (finding that there was a likelihood of success in claiming copyright protection for "the total concept and feel" of Pac-Man (internal quotation marks omitted)); see also Kyle Coogan, Let's 
In this Article, we discuss the possibility that the $\$ 4$ billion video game streaming industry fails to recognize thousands of joint authors of copyrightable works. 18 If players are joint authors, substantial amounts of money may be reallocated from celebrity streamers to players they compete against. 19 The Article has four substantive parts. In Part II, we discuss the rise of esports, the emergence of video game streaming, and the contracts that govern video games. Part III provides an overview of copyright and its relationship to video games. In Part IV, we analyze the issue of joint authorship, both as it pertains to relationships between players and game makers, and as it pertains to relationships among players. Finally, before concluding, in Part V, we discuss the strategic implications of our findings.

\section{AN OVERVIEW OF THE ESPORTS ENVIRONMENT}

Esports represents one of the most exciting and fastest growing segments of the entertainment market. 20 Viewership of top esports tournaments now surpasses that of prestigious sporting events like the Kentucky Derby and the Daytona 500.21 But esports are not as new as some may believe. Indeed, they have their origins in pinball machines that once dotted the backs of supermarkets and bodegas before many states in

Play: A Walkthrough of Quarter-Century-Old Copyright Precedent as Applied to Modern Video Games, 28 Fordham Intell. Prop. Media \& Ent. L.J. 381, 394-95 (2018).

18 Twitch alone has a value of about $\$ 3.79$ billion. Lucas Fortney, How Amazon's Twitch Platform Makes Money, InvesTopedia (Oct. 20, 2019), https://www.investopedia.com/investing/how-does-twitch-amazons-videogame-streaming-platform-make-money/ [https://perma.cc/6RQ8-GM7M].

19 See infra Section IV.B.

20 See Christopher Ingraham, The Massive Popularity of Esports, in Charts, WAsh. Post (Aug. 27, 2018, 2:59 PM),

https://www.washingtonpost.com/business/2018/08/27/massive-popularityesports-charts/ [https://perma.cc/B7QN-ZPWR].

21 Id. 
the late 1940s and early 1950s argued that they were illegal gambling devices. 22

As computing power began to grow, so too did an interest in recreational pursuits surrounding computers. ${ }^{23}$ During the 1960s, MIT students created the first computerized video game using Cathode Ray Tube monitors and a PDP-1 computer.24 The game, dubbed Spacewar!, was the predecessor to games like Space Invaders, Asteroids, and Missile Command.25 Visionaries soon recognized the opportunity to commercialize video gaming. 26

In 1972, Nolan Bushnell launched Atari-the first successful American video game company.27 Atari made headlines with Pong, which was first available in arcades and then on home consoles. 28 Bushnell used the money from Pong to expand Atari's popularity. ${ }^{29}$ Atari's dominance did not last, however, as others saw the potential for a lucrative future in video gaming and sought to enter the marketplace. 30 Early competition centered on arcades, 31 but market forces

22 John T. Holden, Marc Edelman \& Thomas A. Baker III, A Short Treatise on Esports and the Law: How America Regulates Its Next National Pastime, 2020 U. ILL. L. REV. 509, 513.

23 See David R. Hussey, Reading into the Cold War in Video Games, Play THE PAST (Oct. 1, 2013), https://www.playthepast.org/?p=4101 [https://perma.cc/M8CK-94CZ].

24 Holden et al., supra note 22, at 514.

25 Jeff Spry, Firsts: Spacewar! Was the World's First Video Game, SYFY WIRE (Jan. 29, 2018, 1:00 PM), https://www.syfy.com/syfywire/firstsspacewar-was-the-worlds-first-video-game [https://perma.cc/V79N-JTY5].

26 See Holden et al., supra note 22, at 514.

27 Benj Edwards, The Untold Story of Atari Founder Nolan Bushnell's

Visionary 1980s Tech Incubator, FAST Co. (Feb. 17, 2017), https://www.fastcompany.com/3068135/the-untold-story-of-atari-foundernolan-bushnells-visionary-1980s-tech-incubator [https://perma.cc/2LZUYH3S].

$28 I d$.

29 See id.

30 See Laura June, For Amusement Only: The Life and Death of the American Arcade, THE Verge (Jan. 16, 2013, 10:00 AM), https://www.theverge.com/2013/1/16/3740422/the-life-and-death-of-theamerican-arcade-for-amusement-only [https://perma.cc/MH7K-K8Q9].

31 See id. 
eventually focused the industry on the in-home console gaming system. 32

By the mid-1980s, multiple companies were vying for market share in the video gaming space. 33 Japanese company Nintendo entered the U.S. market in 1985, launching its landmark Nintendo Entertainment System (NES) and its proprietary chip system, which prevented third parties from making NES-compatible games-a feature whose absence would eventually doom Atari's offerings. ${ }^{34}$ By the end of the decade, SEGA's Genesis system was the prime competitor to the NES. 35

The 1990s saw the professionalization of video gaming. Dennis Fong became the first professional video game player, notably winning the 1997 "Red Annihilation" Quake tournament in Atlanta, Georgia. 36 In 1998, Blizzard released StarCraft, which catalyzed the launch of various professional esports leagues in South Korea. 37

In the early 2000s, professional esports expanded with the launch of the World Cyber Games. ${ }^{38}$ The launches of the Electronic Sports World Cup and Major League Gaming

32 Jordan Minor, Console Wars: A History of Violence, PCMAG (Nov. 11, 2013), https://www.pcmag.com/article/317739/console-wars-a-history-ofviolence [https://perma.cc/WY2L-4NB8].

33 Holden et al., supra note 22, at 515.

34 See id.

35 See id.

36 Chris Baker, Meet Dennis 'Thresh' Fong, the Original Pro Gamer, Rolling Stone (Aug. 30, 2016, 9:35 PM), https://www.rollingstone.com/culture/culture-news/meet-dennis-threshfong-the-original-pro-gamer-103208/ [https://perma.cc/36NP-BSE6].

37 See Kevin Hovdestad, The Rise and Fall of StarCraft II as an eSport, IGN (last updated May 7, 2020, 4:17 PM), https://www.ign.com/articles/2016/03/22/the-rise-and-fall-of-starcraft-ii-asan-esport [https://perma.cc/MJA5-Z76Q]. The popularity of StarCraft as a top-level esports title fell after the arrest of a few top players for their roles in fixing games. See Shaun Prescott, Eight Arrested in StarCraft II MatchFixing Scandal, PC GAMER (Apr. 22, 2016), https://www.pcgamer.com/eightarrested-in-starcraft-ii-match-fixing-scandal/ [https://perma.cc/6JKZ-ZCBG] (discussing the scandal).

38 See Holden et al., supra note 22 , at 518. 
followed.39 The latter would be the first esports league to obtain a television broadcasting contract, and one of the first endeavors to bring esports out of a niche community of gamers and into mainstream popularity. 40 In 2015 , the game maker Activision Blizzard acquired Major League Gaming, ${ }^{41}$ which remains one of the most successful esports broadcasting properties. ${ }^{42}$ Today's leagues vary in structure and attract significant investor interest due to the long-term potential of the industry. 43

39 See id. at 518-19.

40 See Major League Gaming Esports, EsPORTBET, https://esportbet.com/major-league-gaming/ [https://perma.cc/XJ3Z-JCK9] (last visited Sept. 15, 2020) (discussing history of Major League Gaming).

41 See Holden et al., supra note 22, at 518-19.

42 Major League Gaming has prospered for nearly twenty years, in part because of its innovation and well-produced events. See Cody Luongo, No. 1 in Esports: Major League Gaming Continues to Bring Industry's Vision to Life, THE Lines (last updated Jan. 22, 2018),

https://www.thelines.com/major-league-gaming-captures-esports-vision/ [https://perma.cc/2JG5-CQFM].

43 See John T. Holden \& Thomas A. Baker III, The Econtractor? Defining the Esports Employment Relationship, 56 AM. Bus. L.J. 391, 399413 (2019). 
The esports industry 44 has grown tremendously in recent years, 45 but the larger video gaming industry dwarfs it. $46 \mathrm{On}$ one estimate, the global gaming market was worth approximately $\$ 138.7$ billion in 2018 and projected to grow about ten percent in 2019.47 Some analysts predict an industry value as high as $\$ 300$ billion by 2025.48

The popularity of esports leagues and competitions as investments stems partly from the demographics of the

44 The esports industry represents a variety of different game genres, though they can be grouped into six broad categories: fighting games, firstand third-person shooter games, real-time strategy games, sports games, multiplayer online battle arena (MOBA) games, and all other games. See Holden et al., supra note 22, at 524-28 (2020). MOBA games like League of Legends and first- and third-person shooter games like Counter-Strike: Global-Offensive and Fortnite are among the most popular esports titles. See $i d$. at 525, 527. Each esports genre requires a slightly different skill set, with some games rewarding cerebral play and others rewarding quick reaction time. See id. at 524-28.

45 See Hilary Russ, Global Esports Revenues to Top $\$ 1$ Billion in 2019: Report, REUTERS (Feb. 12, 2019, 11:05 AM),

https:/www.reuters.com/article/us-videogames-outlook/global-esportsrevenues-to-top-1-billion-in-2019-report-idUSKCN1Q11XY (on file with the Columbia Business Law Review) (noting projected global esports revenues of $\$ 1.1$ billion in 2019).

46 See Kevin Anderton, The Business of Video Games: Market Share for Gaming Platforms in 2019, ForBes (June 26, 2019, 6:00 AM), https://www.forbes.com/sites/kevinanderton/2019/06/26/the-business-ofvideo-games-market-share-for-gaming-platforms-in-2019-infographic [https://perma.cc/WZ5J-BHKB] (reporting the size of the video gaming industry. One of the recent drivers of growth in the video game industry has been the popularity of free-to-play games, which do not charge users to download the game but instead allow users to make in-game purchases. See Ilker Koksal, Video Gaming Industry \& Its Revenue Shift, ForBEs (Nov. 8, 2019, 5:50 PM), https://www.forbes.com/sites/ilkerkoksal/2019/11/08/videogaming-industry-its-revenue-shift/\#3bbe1668663e [https://perma.cc/PLD6-YS36].

47 Anderton, supra note 46.

48 Liz Lanier, Video Games Could Be a $\$ 300$ Billion Industry by 2025 (Report), VARIETY (May 1, 2019, 2:00 PM),

https://variety.com/2019/gaming/news/video-games-300-billion-industry2025-report-1203202672/ [https://perma.cc/V3EZ-RWGA]. 
industry's consumers. 49 League of Legends, the most popular esports title, attracts up to eight million concurrent players during peak times.50 Top esports championships like the League of Legends World Championship attract more than ten times the viewership of some major sporting events, including the U.S. Open golf tournament.51 While forty percent of young Americans identify as fans of the National Football League, thirty-eight percent identify as fans of esports. 52

\section{A. A Brief Overview of Streaming}

Video game streaming has blossomed as a sub-industry of esports. 53 The video game streaming market centers around "streamers": individuals who record and broadcast commentary of their own or others' video game play. 54 Prominent streamers enjoy millions of followers on their online channels and can generate millions of dollars each year

49 See Ingraham, supra note 20 (describing a poll finding disproportionate esports involvement among Americans aged fourteen to twenty-one).

50 Dustin Bailey, League of Legends Player Count Reaches Eight Million Concurrent Users, PCGAMEsN (Sept. 18, 2019),

https://www.pcgamesn.com/league-of-legends/player-count [https://perma.cc/QPB8-4SQ9].

51 See Ingraham, supra note 20.

52 See id. Although esports continue to grow in popularity, by any estimate the traditional sports industry remains substantially more valuable. See Raul Amoros, Which Professional Sports Leagues Make the Most Money, HowMuch (July 1, 2016), https://howmuch.net/articles/sportsleagues-by-revenue [https://perma.cc/5M73-3RFJ] (noting the revenues generated by various professional sports leagues).

53 See Darren Geeter, Twitch Created a Business Around Watching Video Games-Here's How Amazon Has Changed the Service Since Buying It in 2014, CNBC (last updated Feb. 26, 2019, 12:29 PM), https://www.cnbc.com/2019/02/26/history-of-twitch-gaming-livestreamingand-youtube.html [https://perma.cc/68NG-3AE9].

54 See Patricia Hernandez, The Twitch Streamers Who Spend Years Broadcasting to No One, THE VERGE (July 16, 2018, 9:50 AM),

https://www.theverge.com/2018/7/16/17569520/twitch-streamers-zeroviewers-motivation-community [https://perma.cc/LWS3-DGKZ]. 
in endorsements and donations.55 In fact, certain video game streamers are more popular than professional esports players. 56

Streaming on a platform such as Twitch or YouTube requires very little: a computer, internet access, a microphone, a camera, and downloadable software.57 Beyond this, a streamer's success depends on their ability to secure and maintain an audience. After establishing a following, a streamer on a site like Twitch can grow their presence, eventually gaining the ability to monetize their streams. ${ }^{58}$

55 See Jordan Smith, The Top 10 Highest Paid Streamers in the World (and How They Make Money), FilTERGRAde (Nov. 11, 2019),

https://filtergrade.com/top-10-highest-paid-streamers-in-the-world/ [https://perma.cc/UU65-S4H2].

56 See Sam Nordmark \& Carolyn Zou, Live Streamer or Competitive Gamer-Which Career Makes the Most Sense?, Dot EsPorTs (Sept. 2, 2020, 5:10 PM), https://dotesports.com/general/news/esports-vs-streamingmoney-career-31144 [https://perma.cc/ZAU5-6QG5].

57 Michael Andronico, The Ultimate Guide to Twitch: The Tips, Tricks and Gear You Need, Tom's Guide (July 14, 2020),

https://www.tomsguide.com/us/twitch-streaming-guide,review-3009.html [https://perma.cc/MNQ4-G9LM] (noting the key components necessary for streaming on Twitch).

58 On Twitch, streamers progress through levels. The first level is a Twitch "affiliate," which requires streamers, over a thirty-day period, to broadcast at least 500 minutes with a minimum of seven unique broadcasts and a minimum of three concurrent viewers. See Kismet, Becoming a Twitch Affiliate and Partner Guide, STREAMElEments (Sep. 28, 2017),

https://blog.streamelements.com/becoming-a-twitch-affiliate-and-partnerguide-8990d7fe25ac [https://perma.cc/F27K-MZ3R]. Additionally, streamers must have at least 50 followers to become an affiliate. See id. After becoming a Twitch affiliate, streamers can become Twitch "partners" with an increase in streaming time and average viewership. See Achievements, TwITcH,

https://help.twitch.tv/s/article/achievements?language=en_US\#Partner[htt ps://perma.cc/KFH8-P4Q5] (last visited Nov. 27, 2020); Twitch Partner Program, TwiTch (last visited Dec. 9, 2020),

https://www.twitch.tv/p/partners/ [https://perma.cc/N4NP-XBMK] (suggesting that streamers working toward partnership should consider the affiliate requirements, which include the aforementioned follower requirement). 
The potential to earn life-changing amounts of money drives many to try their hands at streaming, though the streaming model may be highly profitable for only a small number of those who engage in it. 59

Several companies appear to have foreseen at an early stage the growth of video game streaming. For instance, Amazon acquired Twitch in 2014 for around $\$ 1$ billion.60 Twitch now controls seventy-six percent of the video game streaming market across the United States and Europe. 61

YouTube has a simpler program to monetize broadcasts, allowing websites to place advertisements on streams. See Carla Marshall, How-to Make a Living From YouTube's Partner Earnings, TUBULAR Insights (Oct. 23, 2013), https://tubularinsights.com/youtube-partner-earnings/ [https://perma.cc/UK2F-SFXK]. Streamers usually receive shares between about $\$ .30$ and $\$ 2.50$ per thousand views, though some content producers earn significantly more. See id.

Facebook's gaming platform compensates qualified streamers based on the number of stars they receive during a stream. See Nick Miller, Support Your Favorite Creator with Stars, FACEBook: GAMing (June 25, 2018), https://www.facebook.com/fbgaminghome/blog/support-your-favoritecreator-with-stars [https://perma.cc/3YA4-323D]. Each star is worth $\$ 0.01$, and viewers can purchase stars to give to streamers. See id. Facebook gaming employs the "Level Up Program" under which streamers must meet certain broadcast thresholds to qualify for star compensation. See John Imah \& Nick Miller, Introducing the Facebook Gaming Creator Level Up Program, FACEBOOK: GAMING (June 7, 2018),

https:/www.facebook.com/fbgaminghome/blog/introducing-the-facebookgaming-creator-level-up-program [https://perma.cc/6RRJ-RJ9C]. In particular, streamers must create a web page, broadcast a minimum of four hours over a fourteen-day period, and broadcast on at least two of those days. See id. They also must have 100 followers on their page. See id.

59 Cf. Jim Wang, How Much Do Twitch Streamers Make in 2020?, BEST WALLET HACKS (last updated June 7, 2020),

https://wallethacks.com/how-much-do-twitch-streamers-make/ [https://perma.cc/LR7P-GCP2] (discussing pay rates of popular Twitch streamers but acknowledging them to be atypical).

60 Nick Wingfield, What's Twitch? Gamers Know, and Amazon Is Spending \$1 Billion on It, N.Y. TIMES (Aug. 25, 2014), https://www.nytimes.com/2014/08/26/technology/amazon-nears-a-deal-fortwitch.html [https://perma.cc/AC4G-UTBM].

61 Imad Khan, Why Twitch Is Still the King of Live Game Streaming, N.Y. Times (Dec. 15, 2019), 
Companies like Microsoft have responded by purchasing rival streaming sites and poaching some of Twitch's top streamers, signing them to exclusive deals. 62 They are competing for the patronage of hundreds of millions of consumers, including the more than 700 million people per month who, in 2019, played, viewed, or discussed video games on Facebook alone.63 Together, Facebook, Twitch, and YouTube users watch about 3.5 billion hours of content quarterly, with Twitch users responsible for about three-quarters of those hours. 64

The growth of streaming happened despite doubts about users' rights to stream game content when underlying intellectual property rights appear to belong to game companies.65 Indeed, Twitch complies with Digital Millennium Copyright Act (DMCA) requests to remove infringing content. 66 Despite this threat, streamers make a living on sites like Twitch by monetizing content from video games. 67

This raises the question as to what rights video game companies have to order the takedown of content or draw a

https://www.nytimes.com/2019/12/15/business/tech-video-game-streamingtwitch.html [https://perma.cc/6852-BGQE].

62 See, e.g., id.

63 See id.

64 See Tiffany Hsu, Twitch Users Watch Billions of Hours of Video, but the Site Wants to Go Beyond Fortnite, N.Y. Times (last updated June 29, 2020),

https:/www.nytimes.com/2019/09/26/business/media/twitch-twitchcon-adsredesign.html [https://perma.cc/52XQ-ZBZD].

65 See Christian Genetski \& Christian Troncoso, Copyright Industry Perspectives: The Pivotal Role of TPMs in the Evolution of the Video Game Industry, 38 COLUM. J.L. \& ARTs 359-60 (2015) (discussing game companies' success in wielding copyrights).

66 Some DMCA takedown notices sent to Twitch streamers have involved the unlicensed streaming of music within broadcasts. See Scott Alan Burroughs, A Twitch in Time: Legal Issues Catch up with Popular Game-Broadcasting Platform, ABove THE L. (Sep. 5, 2018 11:27 AM), https:/abovethelaw.com/2018/09/a-twitch-in-time-legal-issues-catch-upwith-popular-game-broadcasting-platform/ (on file with the Columbia Business Law Review).

67 See id. 
share of the profits generated by streamers.68 Copyright holders have issued many DMCA takedown notices to streamers for using music without permission, but some game companies have also attempted to shut down select streamers using DMCA complaints.69 Nevertheless, the apparent infrequency with which game companies issue takedown notices to streamers for broadcasting game play leaves doubtful the question of what specific rights streamers and game companies have in streamed content.

The challenge for some streamers is that their financial livelihoods center on their ability to continue streaming content-a precarious situation if, as some (including the authors of this Article) suggest, the streams are unauthorized derivative works. 70 Some of those same voices, however, posit that streaming may be a fair use. 71 That issue remains without a clear answer, and its resolution may be fact- and game-dependent. With video game streaming expected to produce $\$ 3.5$ billion in revenue by 2021 , game companies are likely to reexamine the issue and reevaluate whether to allow streamers to monetize video game content without

68 See id. (discussing uncertainty around "who-owns-what").

69 Willie Clark, The (Still) Uncertain State of Video Game Streaming Online, ARs TECHNICA (Jan. 28, 2018, 9:00 AM), https://arstechnica.com/gaming/2018/01/to-stream-or-not-to-stream-howonline-streaming-game-videos-exist-in-an-ip-world/

[https://perma.cc/M5T3-XFFE] (noting that a game developer sent a DMCA takedown notice to streamer after the streamer used a racial slur during a live stream); see also Riley MacDonald, Mass DMCA Takedown Requests Issued on Twitch, LEXOLOGY (June 18, 2020), https://www.lexology.com/library/detail.aspx?g=89212f93-8b5e-4a47-b9db954ae84675e7 [https://perma.cc/UV29-ZHZP] (reporting that the Recording Industry Association of America sent music-related DMCA notifications "en masse" to Twitch streamers in June 2020).

70 See Clark, supra note 69 (relating a streamer's uncertainty about his legal situation).

71 See id. (quoting one streamer's argument to this effect); Dan Hagen, Note, Fair Use, Fair Play: Video Game Performances and "Let's Plays" as Transformative Use, 13 WASH. J.L. TECH. \& ARTS 245, 273 (2018) ("Let's Plays and other similar media ought to have a strong presumption in favor of fair use."); see also Coogan, supra note 17, at 397-99 (discussing arguments for and against fair use). 
interference or to take a more aggressive enforcement approach. 72

The relationship between game companies and players begins with the companies' End User License Agreements (EULAs). $73 \mathrm{We}$ discuss these contracts below in preparation to discuss unexplored issues of streaming and copyright: what rights do competitors and teammates have with regard to streamed content?

\section{B. The EULA and Contracts}

Businesses commonly attempt to control their relationships with consumers contractually. ${ }^{74}$ Video game companies do this through three principal types of agreements: EULAs, Terms of Use Agreements, and Terms of Service Agreements.75 We refer to these agreements collectively as EULAs, since they do not differ materially. 76

Users of physical software, like a tangible video game cartridge or a compact disc purchased in a store, often first encounter these agreements after opening the package

72 See Aaron Swerdlow, The Emerging Legal Battle over Video Game Streaming Rights, Venture BEAT (May 27, 2017, 6:00 AM), https://venturebeat.com/2017/05/27/the-emerging-legal-battle-over-videogame-streaming-rights/ [https://perma.cc/YP79-LXAN].

73 For an overview of EULAs, see generally Annalee Newitz, Dangerous Terms: A User's Guide to EULAs, ElEc. FronTIER Found. (Feb. 17, 2005), https://www.eff.org/wp/dangerous-terms-users-guide-eulas [https://perma.cc/T7CM-A89R]; see also Hilary Smith, Note, The Federal Trade Commission and Online Consumer Contracts, 2016 ColuM. Bus. L. REV. 512, 514-23 (surveying issues related to EULAs in the broader online market).

74 See Ashley Saunders Lipton \& Robert D. Brain, Videogame LaW: Cases, Statutes, Forms, Problems \& Materials 589 (2d ed. 2016).

75 See id. at 590; see also Miriam A. Cherry, A Eulogy for the EULA, 52 DUQ. L. REV. 335, 336-37 (2014) (describing the use of EULAs, which courts have widely upheld in their various forms absent unconscionability).

76 The principal difference is that EULAs are applicable only to the end user, whereas the Terms of Use and Terms of Service Agreements may affect other parties and their transactions. See LIPTON \& BRAIN, supra note 74 , at 590 . 
containing the product.77 In digital transactions, users may encounter EULAs as click-through agreements.78 Two threshold questions are when and to what extent these agreements are enforceable.

The validity of EULAs has a relatively short history dating back to the late 1990s.79 There were two early arguments advanced against the enforceability of these agreements. The first was that they are unenforceable because users only learn about them after purchasing products. 80 The second argument was that the agreements are unconscionable, because they are not the subject of meaningful negotiations. 81

ProCD, Inc. $v$. Zeidenberg was one of the first cases to address the enforceability of terms of service contained in a click-through license. 82 The Seventh Circuit held that a clickthrough agreement was enforceable, because when presented with the option of agreeing to the terms, the user could have rejected the terms and sent the software back to the manufacturer. ${ }^{83}$ Thus, by agreeing and proceeding, the user was bound to the terms.

77 See id.

78 See id.

79 See, e.g., generally Hill v. Gateway 2000, Inc., 105 F.3d 1147 (7th Cir. 1997) (holding that terms included in the packaging of a computer were enforceable even though they were unavailable to the ordering consumers until the computer arrived); cf. also Klocek v. Gateway, Inc., 104 F.Supp.2d 1332, 1332-42 (D. Kan. 2000) (refusing to decide whether an arbitration provision contained in a manual accompanying a computer bound the computer's purchaser).

80 See LIPTON \& BRAIN, supra note 74, at 590.

81 See $i d$. In itself, the fact that EULAs may be contracts of adhesion does not render them invalid. See Davidson \& Assocs. v. Jung, 422 F. 3d 630, 633-35, 639 (8th Cir. 2005) (holding that a clause prohibiting reverse engineering and contained in a click-through agreement drafted by a game maker was enforceable).

82 ProCD, Inc. v. Zeidenberg, 86 F.3d 1447, 1448-49 (7th Cir. 1996). The ProCD decision has, over time, attracted both supporters and opponents. See Mark A. Lemley, Terms of Use, 91 Minn. L. REV. 459, 461 \& n.5, 462 (2006) (noting a substantial volume of commentary, including contract law and preemption criticisms).

83 ProCD, 86 F.3d at 1451, 1455. 
In Davidson \& Associates v. Internet Gateway, the Eastern District of Missouri analyzed whether a group of defendants breached contractual agreements contained within a EULA by circumventing protections against duplication of computer games made by Blizzard Entertainment. 84 After arguing lack of acceptance, the defendants asserted that the contract was an unconscionable contract of adhesion. 85 The court found that the defendants' ability to purchase a different video game meant that the unequal bargaining power between the two parties was not procedurally unconscionable.86 The court drew further support from the thirty-day window during which the defendants could review the EULA and return the game if they objected to any of its terms. 87

EULAs are not, however, universally enforceable. In a 2020 opinion from the Northern District of California, the court refused defendant Epic Games' motion to compel arbitration based upon the Fortnite EULA.88 The court allowed the plaintiff to avoid the EULA because he was a minor, and a minor's contracts "may be disaffirmed . . . before majority or within a reasonable time afterwards[.]" 89

Academics have suggested other limitations. Ochoa raises the possibility that video game EULAs might be void for "violat[ing] public policy."90 Burk adds that a EULA may not resolve all issues if it does not address a specific topic or if its drafters did not foresee a specific use. 91 Another commentator suggests that implied licenses may circumvent EULAs in

84 See Davidson \& Assocs., Inc. v. Internet Gateway, Inc., 334 F. Supp. 2d 1164, 1169-71 (E.D. Mo. 2004), aff'd sub nom. Jung, 422 F.3d 630 (8th Cir. 2005).

85 See id. at 1178-80.

86 See id. at 1179-80.

87 See id.

88 Doe v. Epic Games, Inc., 435 F. Supp. 3d 1024, 1038 (N.D. Cal. 2020).

89 Id. at 1035 (internal quotation marks omitted) (quoting Cal. Fam. Code $\$ 6710)$.

90 Tyler T. Ochoa, Who Owns an Avatar? Copyright, Creativity, and Virtual Worlds, 14 VAND. J. ENT. \& TECH. L. 959, 965 (2012).

91 Dan L. Burk, Owning E-Sports: Proprietary Rights in Professional Computer Gaming, 161 U. PA. L. REV. 1535, 1545 (2013). 
certain instances.92 Additional concerns regarding the international enforceability of EULAs are outside the scope of this Article,93 but they are important to the global phenomenon of modern gaming. 94

Despite potential limitations, game companies widely employ EULAs, and their terms are likely to be factors in determining what content a user can exploit on streaming services like Twitch or YouTube.95 The specific rights game companies grant to users in EULAs vary widely.96 Each gaming company has its own terms regarding distribution of user-generated content, ranging from permissive to heavily restricted. 97

For example, game maker Activision Blizzard, which makes titles such as StarCraft II, states: "You may use the Platform for your personal and non-commercial entertainment purposes only, unless specifically allowed under the terms of this Agreement."98 The limitations of the Blizzard license are meaningful and would appear to limit any

92 See Michael McTee, E-Sports: More than Just a Fad, 10 OKLA. J.L. \& TECH., no. 1, 2014, at 1, 23 ("[C]ourts may see that [a game company's] cooperation with tournament organizers and players creates an implied permission to use the game in a competitive capacity [notwithstanding EULAs.]").

93 See Michael D. ScotT et Al., Scott on Multimedia Law $§ 24.09$, Westlaw (database updated July, 2020) ("[T]he international appeal of virtual worlds may create additional enforceability issues.”).

94 See Esports Interactive Platform, The History of Esports-from Humble Beginnings to Global Phenomenon, MEDIUM (Apr. 3, 2018), https://medium.com/eiplatform/the-history-of-esports-from-humblebeginnings-to-global-phenomenon-fb071e2f38b1 [https://perma.cc/UD9V288X] (describing the rise of esports as a global industry).

95 See Nicholas Robinson, From Arcades to Online: Updating Copyright to Accommodate Video Game Streaming, 20 N.C. J.L. \& TECH. 286, 323-24 (2018).

96 See Elizabeth Brusa, Comment, Professional Video Gaming: Piracy That Pays, 49 J. Marshall L. Rev. 217, 256 \& n.255 (2015).

97 See id. at $256 \&$ n.255, $257 \&$ n.256.

98 Blizzard End User License Agreement, BlizZARD, (last updated Oct. 9, 2020) https://www.blizzard.com/en-us/legal/fba4d00f-c7e4-4883-b8b91b4500a402ea/blizzard-end-user-license-agreement [https://perma.cc/ZC55-6SYS]. 
commercialization of game play without permission from the game maker. 99

Other companies have taken a different approach to users streaming gameplay footage. 100 Riot Games-who makes the most watched esports title, League of Legends-states that it owns all data and content associated with the game and users "can't create any work of authorship based on the Game Content or Riot Services except as expressly permitted by us,"101 while still allowing certain revenue-generating streaming. 102

Electronic Arts takes a still different and more permissive approach. It does not expressly limit gamers' rights to create derivative works in their audiovisual gameplay, allowing for the creation of potentially valuable intellectual property. 103 The company's EULA does not address streaming, but its website states that the company "does not object to [commercial] fair uses of video footage" through services like YouTube. 104 These provisions give players a potentially wide scope of available rights.

99 See id. This appears to reflect a stricter policy than the company employed previously. As Elizabeth Brusa notes, in 2014 Blizzard's EULA explicitly allowed users to engage in paid partnerships with Justin.tv (the predecessor to Twitch) and YouTube. See Brusa, supra note 96, at 257 n.257.

100 See Riot Games Terms of Service, RIOT GAMES (last updated Jan. 15, 2020),

https://na.leagueoflegends.com/en/legal/termsofuse\#dmca [https://perma.cc/AHQ6-56MZ] .

101 See id.

102 See Legal Jibber Jabber, RIOT GAMEs (last updated Aug. 2018), https://www.riotgames.com/en/legal [https://perma.cc/7J7W-PEAR]. Among other things, the company allows "individual players to solicit personal donations or offer subscription-based content while live-streaming games, so long as non-subscribers can still watch the games concurrently." Id.

103 See Electronic Arts User Agreement, ELEC.ARTs (last updated Sept. 8, 2020), https://tos.ea.com/legalapp/WEBTERMS/US/en/PC/ [https://perma.cc/CBG4-J4TN] (contemplating the possibility of usergenerated derivative works).

104 How to Request Permission to use EA Content, Elec. ARTs (Mar. 27, 2020), https://help.ea.com/en-us/help/faq/how-to-request-permission-for-eagames-content/ [https://perma.cc/P287-XJYY]. 
Historically permissive game maker Valve,105 has taken another approach. It specifically limits users' abilities to creative copyrighted derivative works, 106 but it does not mention streaming within its terms.107 Despite this, the company has incorporated features into its offered software allowing users to stream content. 108 The absence of specific authorization, however, may leave streamers in a more precarious legal position than users of games distributed by other game companies.

Other game companies appear to be far more permissive with what users can stream and whether they can profit. 109 Epic Games, the makers of one of the most popular video games of all time (Fortnite),110 has a special exception from their general ban on users' commercial exploitation of the company's games. The Epic Games EULA states: "Fan Content must have no commercial (i.e., monetary) objective. As an exception to this, fans are permitted to monetize web videos (such as YouTube) with advertisements, so long as those videos otherwise meet the requirements of this Policy."111 The explicit permission to stream content from Epic's games may contribute to the popularity of Fortnite.

105 See Holden \& Baker supra note 43, at 406 (noting that Valve allows a third party to operate an esports league using a Valve game).

106 See, e.g., Square Enix End User License Agreement, STEAM (last visited Oct. 6, 2020), https://store.steampowered.com/eula/eula_39190 [https://perma.cc/T7QA-DD6Q] (containing terms for playing the game Dungeon Siege, which Valve offers through its digital platform).

107 See id.

108 See Michael McWhertor, Valve's New Steam Link Update Lets You Stream Anywhere, Polygon (Mar. 14, 2019, 4:03 PM), https://www.polygon.com/2019/3/14/18266000/steam-link-anywherestreaming-update (on file with the Columbia Business Law Review).

109 See Fan Content Policy, EPIC Games (last visited Sept. 13, 2020), https://www.epicgames.com/site/en-US/fan-art-policy [https://perma.cc/FHN3-X5KP].

110 Laurent Giret, Fortnite Is the World's Most Popular Game, but It Was Almost Cancelled Before It Launched, ONMSFT (June 17, 2019), https:/www.onmsft.com/news/fortnite-is-the-worlds-most-popular-gamebut-it-was-almost-cancelled-before-it-launched [https://perma.cc/99FKQN8D] (noting that Fortnite had more than 250 million users in 2019).

111 Fan Content Policy, supra note 109. 
Because some game companies' EULAs are lenient and others' may be unenforceable, copyright issues can arise. Thus, the ownership of gameplay copyrights ought to be determined. We explore that issue below with an emphasis on the novel issue of whether and when gamers are joint authors of their recorded gameplay. Section III begins the discussion of that issue with an overview of video games' intersection with copyright. The discussion then takes up in more detail the application of specific aspects of copyright doctrine to video games.

\section{COPYRIGHT AND VIDEO GAMES}

In 1982, the Seventh Circuit faced the "question of the scope of copyright protection to be afforded audiovisual games such as PAC-MAN."112 The court found the game to be protectable with regard to its "audio component and the concrete details of the visual presentation," but recognized that certain "standard game devices" (e.g., presentation of the score) are not protectable except from verbatim copying. 113 Applying this standard, the court found infringement based on similarities between Pac-Man and the accused game, including visual similarities to the original characters and their manners of movement. 114

A decade later, future Supreme Court Justice Ruth Bader Ginsburg wrote for a panel of the D.C. Circuit and held that a video game (Atari's 1975 game Breakout) was copyrightable as an audiovisual work. 115 In so holding, she emphasized that

112 Atari, Inc. v. N. Am. Philips Consumer Elecs. Corp., 672 F.2d 607, 615 (7th Cir. 1982); see also Deborah F. Buckman, Annotation, Intellectual Property Rights in Video, Electronic, and Computer Games, 7 A.L.R. Fed. $2 \mathrm{~d}$ 269 (2005) (discussing copyright protection for video games).

113 N. Am. Philips Consumer Elecs., 672 F.2d at 617.

114 See id. at 618-20.

115 Atari Games Corp. v. Oman, 979 F.2d 242, 243 (D.C. Cir. 1992) (citing Feist Publ'ns v. Rural Tel. Serv. Co., 499 U.S. 340 (1991)). This dispute arose after "Atari sought expedited registration of a copyright claim in the audiovisual work embodied in BREAKOUT." Atari Games Corp. v. Oman, 888 F.2d 878, 879 (D.C. Cir. 1989). Its resolution followed the 
the game "would be copyrightable if the requisite [low] level of creativity is met by either the individual [displayed] screens or the relationship of each screen to the others and/or the accompanying sound effects."116 Premised upon this finding, the court ordered the Copyright Office to reconsider the registration applying the proper standard.117

These cases established that the audiovisual outputs of video games are subject to copyright. Building from this basic premise, we consider whether copyright protection is available to game players for audiovisual depictions of their personal gameplay, assuming they satisfy the statutory mandate that these depictions are "fixed in [a] tangible medium" (i.e., recorded). 118 This player-controlled output will, by its nature, include "objects, background scenes, and nonplayer characters" that may be subject to copyrights owned by the game company. 119 Accordingly, we analyze gameplay as a potential derivative work (i.e., one which is "based upon one or more preexisting works"). ${ }^{120}$

Supreme Court's determination that "the requisite level of creativity [for copyright] is extremely low." Feist, 499 U.S. at 345.

116 Oman, 979 F.2d at 244.

$117 I d$. at 247.

118 For the "fixation" requirement, see 17 U.S.C. $§ 102$ (2018). Article I, Section 8 of the U.S. Constitution illuminates this requirement; it grants Congress the power "[t]o promote the Progress of Science and useful Arts, by securing for limited Times to Authors ... the exclusive Right to their respective Writings and Discoveries." U.S. ConsT. art. I, § 8, cl. 8. Consistent with that clause, copyright only extends to "writings," and something is a "writing' under the Constitution only if it is 'fixed in [a] tangible medium of expression'." Cheryl Swack, The Balanchine Trust: Dancing Through the Steps of Two-Part Licensing, 6 VILL. SporTs \& ENT. L.J. 265, 279 (1999) (quoting 1 Melville B. Nimmer \& David Nimmer, Nimmer on Copyright $\S$ 2.03 (1995)).

119 Dan L. Burk, Copyright and Paratext in Computer Gaming, in EMERging Ethical Issues of Life IN ViRTUAL Worlds 26, 30 (Charles Wankel \& Shaun Malleck eds., 2010).

120 See 17 U.S.C. $§ 101$ (2018); see also Clark, supra note 69 (quoting an attorney working in the area: "I think the most legally accurate response right now is that ... most streams are derivative works" (internal quotation marks omitted)); Ball, supra note 13, at 278 (citing Hagen, supra note 71, 
The following subsections provide answers to three threshold questions that are necessary to the creation of copyrightable expression by a game player. First, is it legally possible for a player to create an audiovisual derivative work in their gameplay? Second, does modern gameplay include the requisite level of creativity for copyright to attach? Third, when does fixation (i.e., recording of the creative output) occur, such that it is possible to satisfy the requirement that copyrighted material be recorded?

\section{A. Derivative Works in Gameplay}

In order to obtain a derivative copyright, the author must have permission from the original owner to make the new work. 121 Protection "does not extend to any part of the work in which [pre-existing] material has been used unlawfully." 122 In the instance of video games, this requires the player to have permission to play the game. Permission is usually given when the player agrees to the game's EULA. 123

This requirement does not mean that a derivative author must obtain permission from the original owner to secure copyright protection; that occurs as a matter of law when the

at 248) ("The prevailing argument against copyrighting video game streams is that streams are derivative works.").

121 Mulcahy v. Cheetah Learning, LLC, 386 F.3d 849, 852 (8th Cir. 2004) (" $[\mathrm{T}]$ he creator of an original derivative work is only entitled to a copyright if [he or] she had permission to use the underlying copyrighted work.").

12217 U.S.C. $\S 103(a)$ (2018).

123 See James Gatto \& Mark Patrick, Overview of Select Legal Issues with eSports, 6 ARIZ. ST. SpORTs \& ENT. L.J. 427, 443-444 (2017); Fortnite End User License Agreement, EPIC GAMES (last visited Sept. 13, 2020), https://www.epicgames.com/fortnite/en-US/eula [https://perma.cc/QMK7W6D3] ("Epic grants you a personal, non-exclusive, non-transferable, nonsublicensable limited right and license to install and use the Software on compatible devices you own or control for your personal entertainment use.").

One could also make the case for implied permission to make a derivative work. See Garcia v. Google, Inc., 766 F.3d 929, 937-38 (9th Cir. 2014), rev'd on reh'g on other grounds, 786 F.3d 733 (9th Cir. 2015) (en banc); Effects Assocs., Inc. v. Cohen, 908 F.2d 555, 558-59 (9th Cir. 1990). 
new expression is recorded.124 Creation of a derivative copyright can, however, be defeated by limitations imposed by the original owner.125 As an example of such a limitation, video game companies use EULAs to attempt to govern the scope of the license granted to the player, and some do limit the possibility of creating derivative works. 126

To the extent that players secure rights in their gameplay, "the copyright is limited to the features that the derivative work adds to the original." 127 They receive protection only for their creative additions to their new works. The following subsection discusses what creative "features" players add to an audiovisual recording, and whether this satisfies the creativity standard for copyright.

\section{B. Creativity}

In order to obtain a derivative copyright, the author must exhibit sufficient originality in the new work. 128 This is not a high threshold; in fact, the Supreme Court expressly recognized an "extremely low" bar for creativity to receive a

124 Schrock v. Learning Curve Int'l, Inc., 586 F.3d 513, 515-16 (7th Cir. 2009) ("[C]opyright in a derivative work arises by operation of law-not through authority from the owner of the copyright in the underlying workalthough the parties may alter this default rule by agreement." (citing Liu v. Price Waterhouse LLP, 302 F.3d 749, 755 (7th Cir. 2002))).

125 Schrock, 586 F.3d at 524 ("[T] work author's intellectual-property rights in the contract, license, or agreement that authorized the production of the derivative work." (citing Liu, 302 F.3d at 755)).

126 See Gatto \& Patrick, supra note 123, at 444-45.

127 Pickett v. Prince, 207 F.3d 402, 405 (7th Cir. 2000); see Stewart v. Abend, 495 U.S. 207, 223 (1990) ("The aspects of a derivative work added by the derivative author are that author's property, but the element drawn from the pre-existing work remains on grant from the owner of the preexisting work." (citing Russell v. Price, 612 F.2d 1123, 1128 (9th Cir. 1979))).

128 Mulcahy v. Cheetah Learning LLC, 386 F.3d 849, 852 (8th Cir. 2004) ("A derivative work may itself be copyrighted if it has the requisite originality."). 
copyright. 129 This standard applies to derivative works. $130 \mathrm{We}$ believe that players of modern massively multiplayer online games satisfy this standard. 131

The creativity embodied in the output of a digital device can be analyzed across a spectrum. In certain instances where user-requested audiovisual output from a digital device is rote and predictable, no user creativity is involved.132 As an extreme example of no creativity, a user hitting play on a DVD player causes an unoriginal, rote audiovisual response (playing the video).133 This action engages the digital device, but produces no new creative, potentially copyrightable content, even assuming that the output was being recorded, as is necessary for copyright to attach.

Early video games are similar, in that they entail a predictable audiovisual response associated with the game's programming and user input. Consider the classic maze game, Pac-Man. To complete levels, users move their avatar around a two-dimensional board to avoid four ghosts while collecting

129 Feist Publ'ns, Inc. v. Rural Tel. Serv. Co., 499 U.S. 340, 345 (1991).

130 Sapon v. DC Comics, No. 00 CIV. 8992, 2002 WL 485730, at *8 (S.D.N.Y. Mar. 29, 2002) ("Feist does not require derivative works to contain more than a modicum of creativity to be protected."). A work containing only a modicum of creativity will, however, enjoy a narrow copyright. This means that only a near-verbatim copy of the derivative work is likely to infringe the derivative copyright. See MyWebGrocer, LLC v. Hometown Info, Inc., 375 F.3d 190, 193-94 (2d Cir. 2004) (observing that a narrow copyright has protects "at least from wholesale verbatim copying.").

131 '"Massively multiplayer' online games are complex video games involving many thousands of players and 'entire worlds of activity, where people can take on and develop multiple identities, create virtual communities, and tell their own stories." Mason v. Mach. Zone, Inc., $140 \mathrm{~F}$. Supp. 3d 457, 459 n.4 (D. Md. 2015), aff'd, 851 F.3d 315 (4th Cir. 2017) (quoting Jack M. Balkin, Virtual Liberty: Freedom To Design and Freedom To Play in Virtual Worlds, 90 VA. L. REV. 2043, 2043 (2004)).

132 This analysis applies to the user without considering any rights the device manufacturer may have.

133 See Neal F. Burstyn, Creative Sparks: Works of Nature, Selection, and the Human Author, 39 CoLUM. J.L. \& ARTs 281, 309 (2015) (suggesting that the use of a DVD player is not an act of authorship). 
pellets. 134 The ghosts behave in three basic patterns: chase (behave in a ghost-specific manner), scatter (move towards a specific location), and frightened (move randomly). 135 During chase mode, each ghost has a preset behavior; for example, the red ghost (Blinky) always moves towards the player's current position. 136 Success in navigating the ghosts is best achieved by repeating specific patterns (e.g., the Cherry or Mid-Fruit patterns) according to the player's current place in the game. 137 No player-side creativity is involved in gameplay where the obstacles, and choices to avoid them, are so limited.

The Third Circuit adopted this position with regard to an early video game called Defender.138 In Williams Electronics, the copyright defendant asserted that "the player's participation withdraws the game's audiovisual work from copyright eligibility because there is no set or fixed performance and the player is a co-author of what appears on the screen." 139 The court rebuffed, stating that despite "some" variation within the audiovisual display, the "repetitive sequence of a substantial portion of the sights and sounds of the game" rendered the game maker the sole author of the audiovisual display. 140 The contemporary Seventh Circuit

134 See Jia-Yue Dai et al., Evolutionary Neural Network for Ghost in Ms. Pac-Man, 2011 InT'L Conf. On Machine LeARning \& Cybernetics 732, 732 (describing the concept of the similar Ms. Pac-Man game).

135 Giovanni Viglietta, Gaming Is a Hard Job, but Someone Has To Do It!, 54 Theory Computing Sys. 595, 613 (2014).

136 Ernest Adams \& Joris Dormans, Game Mechanics: Advanced GAME DESIGN 55 (2012).

137 See Consumer Guide, How To Win at PaC-Man 8-17 (1982) ("It is best to move the Pac-Man by logical and repeatable patterns in order to achieve the highest scores.").

138 See Williams Elecs., Inc. v. Artic Int'l, Inc., 685 F.2d 870, 874 (3d Cir. 1982). The court explained that "[i]n the DEFENDER game, there are symbols of a spaceship and aliens who do battle with symbols of human figures. The player operates the flight of and weapons on the spaceship, and has the mission of preventing invading aliens from kidnapping the humans from a ground plane." Id. at 872 .

139 Williams Elecs., 685 F.2d at 874.

140 Id. (citing Stern Elecs., Inc. v. Kaufman, 669 F.2d at 855-56). The court did not specifically state that there is no co-authorship because the player contributes insufficient creative output, but the finding is implied, 
agreed, emphasizing that because of the "limited number of [potential game] sequences" a player could choose to find,"the creative effort in playing a video game is [not] enough like writing or painting to make each performance of a video game the work of the player."141

This conclusion stands in contrast to the unpredictable output of digital technologies that create novel audiovisual responses through complex command entries. As an example, digital keyboards (pianos) operate in a rule-based system where a particular sound is produced in response to keystrokes. This command-response system 142 differs, however, from a digital movie player or Pac-Man game in the nearly infinite outcomes associated with use of these commands. While the unit responds to specific keystrokes with a particular output (i.e., a specific sound), this users' command-based behavior does not preclude the use of creativity. The vast array of potential output (e.g., new songs) facilitates the production of creative, and thus copyrightable, work.

Analyzing video games, commenters invoke similar positions in response to arguments that "all of the elements in a given sequence of game play are those provided by the developer."143 Early commentary centered on in-game avatars (i.e., the player's in-game manifestation or digital depiction). 144 These avatars are created by selecting among a set of game-provided attributes. Ochoa argues, however, that player-created avatars created from these attributes can be sufficiently original to warrant protection. ${ }^{145} \mathrm{He}$ arrived at

given that the court cited to the repeated aspects of the game and enjoined the defendants despite the argument that "the player becomes a co-author of what appears on the screen." Id.

141 Midway Mfg. Co. v. Artic Int'l, Inc., 704 F.2d 1009, 1011-12 (7th Cir. 1983).

142 We use the term "command-response system" to mean a system which accepts a command and then produces a command-specific response.

143 See Burk, supra note 91, at 1548.

144 See, e.g., Ochoa, supra note 90, at 973-76 (providing such commentary).

145 Id. at 974. 
this conclusion despite all of the elements available in avatar creation coming from the game itself (e.g., providing 100 different eye colors to select from). On this point, Ochoa opined that-despite the elements' origin in the game's code- "the program allows the user some freedom to create an avatar's appearance." 146 Whether the requisite level of creativity could be reached is therefore a function of the "degree of freedom that the program provides to the player."147 Per Ochoa, a game with minimal variation for character attributes does not allow for original expression (similar to Pac-Man's predictable gameplay), 148 but a game with substantial avatar variations (analogous to gameplay found in many modern offerings) can allow for creativity.

This point is important because modern video games often permit significant variation. 149 Fortnite, for example, allows up to 100 players, who compete to be the last survivor, to collect and allocate resources in innumerable gameplay variations. 150 And each player selects from a number of selectable skins. ${ }^{151}$ Moreover, the potential for complicated and strategic behaviors in modern games is immense; in certain games (e.g., StarCraft II), competitive players can

146 Id.

147 Id. But cf. Coogan, supra note 17, at 405-09 (recognizing some difficulties for a similar approach).

148 See supra text accompanying notes 133-38.

149 See Burk, supra note 91, at 1548-49 (discussing-implicitly in the context of modern video games-the vast scope for creativity available to players).

150 Jie Cai, Donghee Yvette Wohn \& Guo Freeman, Who Purchases and Why? Explaining Motivations for In-Game Purchasing in the Online Survival Game Fortnite, 2019 CHI PLAY 391, 391-92.

151 Basically, Fortnite skins are "outfits" for the player's character: "it's a custom look for your player character." Fortnite Skins Guide - What You Need to Know, Best Gaming SeTtings (last visited Nov. 29, 2020), https://www.bestgamingsettings.com/fortnite-skins-guide-what-you-needto-know/ [https://perma.cc/VG9L-MTUG]. Skins are not "just another set of clothes for your character to wear. .. . Some skins are essentially their own character[.]" Id. 
engage in hundreds of commands per minute.152 The intersection of many players creates novel game-specific idiosyncrasies (in both tone and strategy) amplified in some games, like League of Legends, by open audio and text messaging features. 153

The fact that most of a player's audiovisual game output 154 involves only the interaction of graphics in which they (presumptively) cannot claim any copyright is not an issue.155 The game company's presumptive copyright protection over a particular background, game item, or action response does not defeat the possibility of a derivative copyright. As the Second Circuit has held, arrangements of elements that an author cannot claim copyright over can still exhibit the modicum of creativity necessary for copyright protection. 156 Future Supreme Court Justice Anthony Kennedy agreed, writing for the Ninth Circuit that "originality may be found in taking the

152 Daniel Bonnar et al., Risk Factors and Sleep Intervention Considerations in Esports: A Review and Practical Guide, 10 SLEEP MED. RsCH. 59, 61 (2019).

153 Bear, Chat Commands, League of Legends (Mar. 10, 2011, 4:17 $\mathrm{PM}$ ), https://support-leagueoflegends.riotgames.com/hc/en-

us/articles/201752704-Chat-Commands (on file with the Columbia Business Law Review) (discussing the mechanisms for chatting in League of Legends).

154 Exceptions to this generalization include user-generated audio or text communications.

$155 C$. McTee, supra note 92, at 23 ("The game creator holds copyright in both the game and the audiovisual elements while player holds a copyright in the avatar, created using the game's system.").

156 See Zalewski v. Cicero Builder Dev., Inc., 754 F.3d 95, 103 (2d Cir. 2014). The court also noted that the level of creativity necessary for protection is consistent across works; categorizing a work as original, derivative, or a compilation "may be useful . . . in some cases, but we reject the idea that works always fall neatly into one of these categories." Id.; see also Satava v. Lowry, 323 F.3d 805, 811 (9th Cir. 2003) ("It is true, of course, that a combination of unprotectable elements may qualify for copyright protection." (citing Apple Comput., Inc. v. Microsoft Corp., 35 F.3d 1435, 1446 (9th Cir. 1994))). 
commonplace"-e.g., existing aspects of a game_-"and making it into a new combination or arrangement." 157

A final possible objection notes that "most courts have concluded that a [traditional] sports game itself (as opposed to a broadcast of the game) is not copyrightable." 158 While the analogy between playing a live action sport and playing a video game is obvious, 159 the conclusion that these undertakings are legally equivalent breaks down upon closer scrutiny.

In an early assessment of creativity in traditional sports gameplay, the Seventh Circuit stated simply that baseball "[p]layers' performances possess the modest creativity required for copyrightability."160 This simple statement attracted significant criticism. ${ }^{161}$ In National Basketball Ass'n $v$. Motorola, the Second Circuit disagreed, recognizing "a general understanding that athletic events were, and are, uncopyrightable." 162 In taking this position, the latter court

157 United States v. Hamilton, 583 F.2d 448, 451 (9th Cir. 1978) (citing Roth Greeting Cards v. United Card Co., 429 F.2d 1106, 1109-10 (9th Cir. 1970)); see also Ball, supra note 13, at 268 ("[T] here is significant creativity in the actual gameplay of a streamer's broadcast. When playing video games, streamers make choices as to where their in-game character will move, how they might solve puzzles, or how they might approach combat.").

158 Hoopla Sports \& Ent., Inc. v. Nike, Inc., 947 F. Supp. 347, 354 (N.D. Ill. 1996) (footnote omitted) (citing Nat'l Basketball Ass'n v. Sports Team Analysis \& Tracking Sys., Inc., 931 F. Supp. 1124, 1142-45 (S.D.N.Y. 1996)).

159 In traditional sports, the player controls their physical body to achieve certain ends. In esports, the player uses a video game controller to control the behaviors of their in-game avatar.

160 Baltimore Orioles, Inc. v. Major League Baseball Players Ass'n, 805 F.2d 663, 669 n.7 (7th Cir. 1986).

161 See Nat'l Basketball Ass'n v. Motorola, Inc., 105 F.3d 841, 847 (2d Cir. 1997) (reading Baltimore Orioles to apply only to broadcasts and explicitly rejecting a broader interpretation); see also Carl A. Kukkonen, III, Be a Good Sport and Refrain from Using My Patented Putt: Intellectual Property Protection for Sports Related Movements, 80 J. PAT. \& TRADEMARK OFF. Soc'Y 808, 812-13 (1998) (discussing some criticisms); Karolina Jesien, Note, Don't Sweat It: Copyright Protection for Yoga . . . Are Exercise Routines Next?, 5 CARdozo Pub. L. PoL'Y \& Ethics J. 623, 636 (2007) (same).

162 Motorola, 105 F.3d at 846-47. 
drew a strong dichotomy between creativity embodied in the gameplay and creativity used in creating a television broadcast of the gameplay. 163

We believe this dichotomy breaks down when applied to video game play. Criticisms of the Seventh Circuit's position focused on its assertion that the gameplay was subject to copyright because it was broadcast as a television show. $164 \mathrm{We}$ agree that if the recording of the game is necessary to copyright creation (which it is), 165 the copyright covers the recording-not the gameplay itself. This point was emphasized by the Second Circuit, which proffered that recording is the hallmark of copyright (not the play itself), as baseball "obviously can be played without cameras."166

While this analysis is correct, it does not foreclose the possibility that playing a game includes creativity. Rather, the Seventh Circuit established the unremarkable position that recording is necessary for copyright to attach. Creativity can exist in an endeavor, but if it is not reduced to a tangible medium (i.e., recorded), copyright protection is impossible. 167 The recording of the gameplay is a separate and distinct requirement for copyright to attach. As will be discussed in the following part, video game players (unlike baseball players) commonly record their gameplay, such that they can overcome fixation issues associated with traditional sports

163 See id. at 846-47.

164 See Baltimore Orioles, 805 F.2d at 674-75.

165 Hoopla Sports \& Ent., Inc. v. Nike, Inc., 947 F. Supp. 347, 354 (N.D. Ill. 1996).

166 Motorola, 105 F.3d at 846-47. It is notable that some argue that difficulties of ownership would arise if sports players held copyright in their gameplay. See C.B.C. Distrib. \& Mktg., Inc. v. Major League Baseball Advanced Media, L.P., 443 F. Supp. 2d 1077, 1103 n.33 (E.D. Mo. 2006), aff'd, 505 F.3d 818 (8th Cir. 2007) (“[W]ere games themselves copyrightable, problems would be created by the number of persons and entities who could claim joint ownership of the games."). We agree. In fact, this paper speaks directly to these "difficulties of ownership." As discussed later, these difficulties do not, however, control whether video game players can be authors for copyright purposes.

167 See 17 U.S.C. $§ 102(a)$ (2018). 
and enjoy copyright protection over the audiovisual depiction of their play. 168

\section{Fixation}

Fixation, a prerequisite to copyright, occurs when expression is recorded in a manner "sufficiently permanent or stable to permit it to be perceived, reproduced, or otherwise communicated for a period of more than transitory duration."169 Early video game cases analyzed whether the audiovisual output of the game itself was sufficiently fixed to be copyrightable. In one case, the defendant argued "that the images in the plaintiff's audiovisual game are transient, and cannot be 'fixed."'170 The court rebuffed the contention, noting "[t]he audiovisual work is permanently embodied in ... the memory devices, from which it can be perceived with the aid of the other components of the game."171 In making this finding, the opinion relied upon the repeated primary elements of the game that were embodied in game's permanent memory. ${ }^{172}$

168 We note that courts commonly rely on the creativity used in capturing a baseball game to warrant copyright protection in its recording. See Motorola, 105 F.3d at 846-47. There is little of this type of creativity in the typical rote capture of video game play. Burk, supra note 91 , at 1554 . This is unimportant to the current assessment. There only needs to be a modicum of creativity for copyright to attach, and the play of the game, as opposed to the recording of the gameplay, supplies that creativity.

16917 U.S.C. $§ 101$ (2018).

170 Williams Elecs., Inc. v. Artic Int'l, Inc., 685 F.2d 870, 874 (3d Cir. 1982); see also Midway Mfg. Co. v. Artic Int'l, Inc., 704 F.2d 1009, 1011 (7th Cir. 1983).

171 Williams Elecs., 685 F.2d at 874 (emphasis deleted) (quoting Stern Elecs., Inc. v. Kaufman, 669 F.2d 852, 855-56 (2d Cir. 1982)).

172 See Williams Elecs., 685 F.2d at 874. In a Note, Joshua Young argued that this is still good law, stating that "Computer programs that users can manipulate to display various audiovisual elements still satisfy the $\$ 101$ fixation requirement because the elements are fixed in memory and the user is merely dictating which fixed elements will be displayed at any given time.” Joshua L. Young, Note, Copyright Protection for Search Results: "Hiybbprqag," "Mbzrxpgjys," and "Indoswiftjobinproduction", 5 HASTINGS SCI. \& TECH. L.J. 191, 200 (2013). 
This line of precedent runs into significant problems for modern games. There is a strong argument that the aforementioned variability and unpredictability of modern games divorce them from the repetition of primary elements relied on above.173 This undermines the position that the game's code "fixes" its audiovisual output. On the point, Burk asserts that this line of argument "has become increasingly absurd as the technology advances [because one] cannot find the audiovisual work of the game in the game code."174 Ochoa agrees, noting that "as video games become more and more complex, and more and more players are permitted to play the game simultaneously, the case for [audiovisual fixation in the source code] becomes less and less persuasive."175

The judiciary has been ambiguous about whether a game's underlying code embodies the audiovisual display of the game. In 2015 , one court stated that a source code copyright includes the "visual elements of the games as they appear on the computer screen."176 Three years later, however, the same district court found that it was "not clear exactly what the scope of [a game developer's] copyright is or how far it extends,"177 noting that "[c]ourts have reached varying conclusions regarding whether an application for a copyright in source code also creates copyright protection for screen displays." 178 And while it remains largely undisputed that game companies retain copyright protection over many audiovisual aspects of their games, it is questionable whether

173 See Williams Elecs., 685 F.2d at 874.

174 Burk, supra note 91, at 1550.

175 Ochoa, supra note 90 at 968.

176 Lilith Games (Shanghai) Co. v. UCool, Inc., No. 15-CV-01267, 2015 WL 5591612, at*7-8 (N.D. Cal. Sept. 23, 2015).

177 Epic Games, Inc. v. Mendes, No. 17-cv-06223, 2018 WL 2926086, at *8 (N.D. Cal. June 12, 2018).

178 Id. (quoting Clarity Software, LLC v. Allianz Life Ins. Co. of N. Am., No. 04-cv-1441, 2006 WL 2346292, at *6 (W.D. Pa. Aug. 11, 2016)). 
they have fixed every gameplay variation possible within their game. 179

A modern view of the issue is that fixation can occur during gameplay itself.180 Displaying a video game requires the audiovisual output to be copied into temporary memory (RAM) on the game server, which some courts find to constitute fixation in a tangible medium.181 Fixation of this nature allows copyright protection to arise for a particular variation of gameplay (e.g., the audiovisual output of that specific game session). In this situation, the gameplayer would be responsible (jointly or solo) for the game's audiovisual fixation. There is support for the "temporary memory" fixation position within the video game realm, 182 but some recent commenters are critical of this view. 183

The crux of the argument is whether a copy of the game's audiovisual output contained in temporary server memory satisfies the statutory requirement that it be "sufficiently

179 Cf. Burk, supra note 119 at 30-31, 33-34 (indicating uncertainty about fixation through source code and discussing the complex gameplay variations possible in games).

180 This means that the actual playing of the game (e.g., the way the game system runs the software) creates a "fixation" that is sufficient to satisfy the requirements of copyright.

181 See MAI Sys. Corp. v. Peak Comput., Inc., 991 F.2d 511, 518 (9th Cir. 1993) (finding that a copy in RAM is fixed); see also Matthew R. Farley, Making Virtual Copyright Work, 41 Golden Gate U. L. REV. 1, 11 (2010) ("[B]ecause virtual-world creations are supported by underlying strings of computer code that are stored on the game developer or host's servers (independent of external communication with any particular user), they very likely meet the requirement of tangibility or fixation.").

182 See W. Joss Nichols, Painting Through Pixels: The Case for a Copyright in Videogame Play, 30 COLUM. J.L. \& ARTs 101, 112 (2007) (citing Robert A. Gorman \& Jane C. Ginsburg, Copyright: Cases and Materials 85-88 (6th ed. 2002)) ("[I]t is clearer now that even entry into temporary computer memory 'fixes' a work of authorship.”); Dan L. Burk, Electronic Gaming and the Ethics of Information Ownership, 4 INT'L REV. INFO. ETHICS 39, 41 (2005) ("Since the audiovisual output of the game is fixed for some duration in computer hardware, copyright law will apply.").

183 See Aaron Perzanowski, Fixing RAM Copies, 104 Nw. U. L. REv. 1067, 1108 (2010) (stating that the foundation of the RAM-based approach "is at best unsteady" and that a replacement is necessary). 
permanent or stable to permit it to be perceived, reproduced, or otherwise communicated for a period of more than transitory duration."184 Speaking to this issue, the Second Circuit adopted a two-element test for fixation: "the work must be embodied in a medium, i.e., placed in a medium such that it can be perceived, reproduced, etc., from that medium (the 'embodiment requirement'), and it must remain thus embodied 'for a period of more than transitory duration' (the 'duration requirement')." 185 The embodiment requirement is not in question in the case of RAM storage. Where the work "can be reformatted and transmitted to the other components" - e.g., the audiovisual output devices of a video game-an embodiment is made. 186

Regarding the duration requirement that the embodiment exist for more than a transitory period, "it is important to remember that the [Copyright] Act does not require absolute permanence for the creation of a copy." 187 On this point, the Second Circuit has contrasted RAM memory that is overwritten in 1.2 seconds (not a copy) with memory that remains until the computer is turned off, which qualified as a copy. 188 Addressing the issue, one district court recognized a "time continuum" upon which some RAM copies will qualify as a fixation and others will not.189 The determination of the

18417 U.S.C. $\S 101$ (2018).

185 Cartoon Network LP v. CSC Holdings, Inc., 536 F.3d 121, 127 (2d Cir. 2008) (citing 2 Melville B. Nimmer \& DAvid Nimmer, Nimmer oN COPYRIGHT $\S 8.02(\mathrm{~B})(3)$ (2007)) (discussing storage in a buffer that, like storage in RAM, was of short duration) .

186 See Cartoon Network, 536 F.3d at 129.

187 Advanced Comput. Servs. of Mich., Inc. v. MAI Sys. Corp., 845 F. Supp. 356, 362-63 (E.D. Va. 1994).

188 Cf. Cartoon Network, 536 F.3d at 129-30 (finding that these facts are "strongly suggest[ive]" of whether a copy satisfies the duration requirement).

189 Advanced Comput. Servs. of Mich., 845 F. Supp. at 363. On this point, the court stated:

$[\mathrm{O}]$ ne need only imagine a scenario where the computer, with the program loaded into RAM, is left on for extended periods of time, say months or years, or indeed left on for the life of the computer. In this event, the RAM version of the 
exact amount of time a video game's output is held in memory is specific to each particular gaming system, game, and system configuration.

There is, however, an additional consideration that favors a determination that gameplay is fixed within the server's temporary memory. The Fourth Circuit contrasted passive transmission of information at the behest of a third party with the creation of a copy that "may be used to serve the computer or the computer owner." 190 The court found no copy to be made by an internet service provider "that automatically receives a subscriber's ... material and transmits it to the Internet at the instigation of the subscriber."191 In contrast, an embodiment made for use by the owner of the temporary memory would likely qualify as a fixation for copyright purposes. 192

A video game server makes copies of gameplay for use by the system and the gameplayer alike. Both parties "use" the copy as the term was understood in the aforementioned case. The gameplayer, using the game server, gains the enjoyment associated with the gameplay; the game company enjoys the benefit of server copies of the gameplay that it intended to be created when playing its game. This analysis favors a determination that copies of video game play created in temporary memory satisfy the fixation requirement for copyright purposes.

program is surely not ephemeral or transient; it is, instead, essentially permanent and thus plainly sufficiently fixed to constitute a copy under the Act. Of course, if a computer is turned off within seconds or fractions of a second of the loading, the resulting RAM representation of the program arguably would be too ephemeral to be considered "fixed" or a "copy" under the Act.

$I d$.

190 See CoStar Grp., Inc. v. LoopNet, Inc., 373 F.3d 544, 551 (4th Cir. 2004).

191 See id.; see also Religious Tech. Ctr. v. Netcom On-Line Commc'n Servs., Inc., 907 F. Supp. 1361, 1369-70 (N.D. Cal. 1995) (finding no infringing copy where the defendant made a temporary copy only at a user's behest).

192 See CoStar Grp., 373 F.3d at 551. 
While a temporary memory copy would be the earliest potential fixation of a user's gameplay, it is not the only possibility. There are multiple ways in which gameplay might later be recorded 193 (fixed in a tangible medium) for future rewatching or analysis.194 For instance, some games automatically record a copy of gameplay for audiovisual replay. 195 Such captures of Fortnite games "are stored locally on your console or PC."196 In that mode, the replay allows the viewer to watch "what the selected player saw during gameplay."197 Digital recording of this nature satisfies copyright's fixation requirement. 198

Lastly, players may create a copy of gameplay outside the video game through independent video capture 199 or use of a

193 By "recording" here, we mean an audiovisual recording of the gameplay that can be played at a later date.

194 See Ochoa supra note 90, at 968 ("[T] the extent that such an improvised live performance [in a game] is itself being simultaneously recorded, ... the resulting audiovisual work will ... qualify as 'fixed." (footnote omitted)). "There is no doubt that broadcasts of sports events (or any other broadcast) may be copyrightable if the event is also recorded." Hoopla Sports \& Ent., Inc. v. Nike, Inc., 947 F. Supp. 347, 354 n.3 (N.D. Ill. 1996) (emphasis added). While Hoopla Sports, in assessing the originality requirement, relied on the creativity of the recording of the sporting event, video game play, rather than the rote conversion of input to audiovisual output, supplies the necessary creativity in the gaming context, at least in most instances. See supra Section III.B.

195 See, e.g., Fortnite Battle Royale - Replay System, EPIC GAMES (Apr. 11, 2018), https://www.epicgames.com/fortnite/en-US/news/fortnite-battleroyale-replay-system [https://perma.cc/LM4U-KUJ7] ("On console your last 10 matches are stored automatically as you play, and on PC your last 100 are stored. These are stored as unsaved replays and will be overwritten as you play more games." (footnote omitted)).

196 Id.

197 Id.

198 Cf. Capitol Recs., LLC v. ReDigi Inc., 910 F.3d 649, 657 (2d Cir. 2018), cert. denied, 139 S. Ct. 2760 (2019) (holding that digital storage of audio file was a copy).

199 See, e.g., generally Online Software Video Capture and Replay System, U.S. Patent No. 9,630,097 (issued Apr. 25, 2017) (describing technology allowing video capture of gameplay). 
streaming application. 200 The first of these options entails the player using video capture software (external to the video game) to create a digital copy of the audiovisual gameplay. 201 With regard to fixation, this digital recording is the same as where the video game creates a copy of gameplay, though as will be discussed later, legal differences may arise concerning joint authorship issues. 202

The second manner of independent gameplay capture may occur contemporaneously with live streaming of a game session. For instance, Twitch offers gamers the ability to share their gameplay via the internet in real time.203 An audiovisual stream can create a copyright so long as "a fixation of the work is being made simultaneously with its transmission." 204 Twitch offers users the option to save a copy of gameplay for later replay from the user's channel.205 A gamer's use of a feature like this creates an audiovisual file and fixes their gameplay. 206

Each of the above methods of fixation arrive at a similar legal conclusion: a copyrighted work is created.207 They may

200 See, e.g., Video on Demand, Twitch (last visited Oct. 7, 2020), https://help.twitch.tv/s/article/video-on-demand?language=en_US (on file with the Columbia Business Law Review) ("A VOD (Video on Demand) is an archive of content previously streamed live on Twitch. Utilizing VODs can help grow your channel and also allow your fans to watch content they may have missed otherwise.").

201 See Ian Paul, The Best Game Capture Software, PCWorLd (Feb. 1, 2019, 4:40 AM), https://www.pcworld.com/article/3040695/the-best-pcgame-video-capture-software-5-top-recording-tools-compared.html [https://perma.cc/YS68-MG6A].

202 See infra Section IV.B.

203 See Quick Start Guide to Streaming on Twitch, TwITCH (last visited Nov. 11, 2020), https://www.twitch.tv/creatorcamp/en/setting-up-yourstream/quick-start-guide-to-streaming-on-twitch/ [https://perma.cc/BGG53JZD].

20417 U.S.C. $\S 101$ (2018).

205 See Video on Demand, supra note 200.

206 Cf. Capitol Recs., LLC v. ReDigi Inc., 910 F.3d 649, 657 (2d Cir. 2018), cert. denied, 139 S. Ct. 2760 (2019) (describing a digital copy of an audio file as a copy of copyright purposes).

207 Ownership of a copyright may depend on who controls the fixation. See infra Section IV.B. 
diverge, however, with regard to which party qualifies as an author for copyright purposes. This divergence is important, as ownership and accounting rights may be a function of authorship. The following section addresses this issue with particular emphasis on whether gamers and game manufacturers may be joint authors.

\section{JOINT AUTHORSHIP}

Parties are joint authors if they prepare a work "with the intention that their contributions be merged into inseparable or interdependent parts of a unitary whole."208 Elements of a whole are considered inseparable "when they have little or no meaning standing alone."209 The contributions likewise must be sufficient to be independently copyrightable. 210 An individual is not a joint author if their "contribution was de minimis."211

Regarding the required "intention" that coauthors work together to form an "inseparable" single expression, individuals need not recognize the legal consequences of their actions. ${ }^{212}$ They simply must maintain an "intent to work

20817 U.S.C. $\S 101$ (2018).

209 BTE v. Bonnecaze, 43 F. Supp. 2d 619, 622 (E.D. La. 1999) (citing Childress v. Taylor, 945 F.2d 500, 505 (2d Cir. 1991); Erickson v. Trinity Theatre, Inc., 13 F.3d 1061, 1068 (7th Cir. 1994)).

$210 I d$. at 625 (collecting cases). There is a line of cases that does not require this element, but in order to put our assertions to the strictest test, we consider it here. See Heimerdinger v. Collins, No. 07CV00844, 2009 WL 1743764, at *5 (D. Utah June 18, 2009) (“Circuits are divided over whether an author in a joint work must have contributed material that is independently copyrightable.”).

211 Words \& Data, Inc. v. GTE Commc'ns Servs., Inc., 765 F. Supp. 570, 575 (W.D. Mo. 1991) ("The respective contributions of authors to a single work do not need to ["]be equal either quantitatively or qualitatively in order to constitute such contributors as joint authors. It would seem, however, that each such contribution must, in any event, be more than de minimis. That is, more than a word or a line must be added by one who claims to be a joint author.[']" (quoting 1 Melville B. Nimmer, Nimmer on COPYRIGHT $§$ 6.07 (1990))).

212 See Childress, 945 F.2d at 508. 
together in the creation of a single product."213 Factors considered in assessing this standard include: "(i) the contributor's decision making authority over what changes are made and what is included in a work, (ii) the way in which the parties bill or credit themselves with regard to the work, (iii) any written agreements with third parties, and (iv) any other additional evidence."214

In a work of joint authorship, the authors maintain equal ownership interests in the work. 215 Each owner is free to use or license the work, subject only to an accounting to their coowners for resultant profits. 216 Authors generally do not have the right to limit how other owners exploit the work. 217

With regard to the audiovisual output of video games and authorship, two classes of parties are of note: gamers and the video game company. The below discusses the potential for, and importance of, company/player and player/player joint authorships.

213 See Janky v. Lake Cnty. Convention \& Visitors Bureau, 576 F.3d 356, 362 (7th Cir. 2009).

214 BTE, 43 F. Supp. 2d at 624-25; accord Tang v. Putruss, 521 F. Supp. 2d 600, 606 (E.D. Mich. 2007) (drawing on Second Circuit precedent in considering "(1) how the parties regarded themselves in relation to the work; (2) the contributor's decision-making authority; (3) agreements with third parties; and (4) other additional pertinent evidence").

215 See Sierra-Pascual v. Pina Records, Inc., 660 F. Supp. 2d 196, 203 (D.P.R. 2009); cf. also 17 U.S.C. § 201(a) ("The authors of a joint work are coowners of copyright in the work.").

216 See Erickson v. Trinity Theatre, Inc., 13 F.3d 1061, 1068 (7th Cir. 1994) ("Each author as co-owner has the right to use or to license the use of the work, subject to an accounting to the other co-owners for any profits."); see also Childress, 945 F.2d at 505 (discussing rights of use); Weinstein v. Univ. of Ill., 811 F.2d 1091, 1095 (7th Cir. 1987) (discussing accounting).

217 See Jasper v. Sony Music Ent., Inc., 378 F. Supp. 2d 334, 346 (S.D.N.Y. 2005) ("It is basic copyright law that joint authors may legally grant a license to a third party to exploit the work without co-author consent." (citing 3 MELVILle B. NIMMER \& DAVID NIMMER, NimMER ON Copyright $§ 610$ (2003))); Mapp v. UMG Recs., Inc., 208 F. Supp. 3d 776, 789-90 (M.D. La. 2016), vacated in part on other grounds, No. 15-602, 2017 WL 3675419 (M.D. La. May 3, 2017) ("While it is well-settled that co-owners of a joint work are free to grant nonexclusive licenses to third parties, there is greater latitude for debate on the issue that arises when co-owners purport to grant exclusive licenses to third parties."). 


\section{A. Game Company/Player Joint Authorship}

The literature has raised the issue of a game company and a player being joint authors. Farley presented, but was dubious of, the argument that a game company and a player could be joint authors of game avatars and virtual objects (e.g., virtual artwork). ${ }^{218} \mathrm{McTee}$ went a step further, supporting the idea by asserting, "Without an arrangement to base the game creator's protection on, the best alternative for copyright ownership of an avatar seems to be joint ownership" between the game maker and player. ${ }^{219}$ While recognizing an imperfect doctrinal fit, Ochoa agreed, stating that "each avatar should itself be considered a joint work between the game provider and the user, and that each avatar should also be considered a contribution to a collective work (the game as a whole)." 220

Nichols extended the position, arguing that the game company and player could be joint authors with regard to recorded game play.221 In consequence, he asserted that a gameplayer would have the ability to seek an accounting if the game company used his or her gameplay in an advertisement or the like.222 Burk was less certain, raising some concern as to whether the game company maintained the requisite intent for joint authorship to occur. 223

Recognizing Burk's concerns, we believe the state of video games has changed, such that it satisfies the requirement that companies and gamers act "with the intention that their contributions be merged into inseparable or interdependent parts of a unitary whole."224 Game companies regularly set forth standards associated with the use and promulgation of

218 See Farley, supra note 181, at 13-16 (arguing that players most likely are sole authors of avatars).

219 See McTee, supra note 92, at 22-23 (discussing reasons for and against joint authorship).

220 Ochoa, supra note 90 , at 991.

221 See Nichols, supra note 182, at 122-24.

222 See id. at 123-24.

223 See Burk, supra note 91, at 1549.

22417 U.S.C. $\S 101$ (2018). 
audiovisual depictions of user gameplay.225 Consistent with case law, "written agreements" support joint authorship, 226 especially where the company affords the player the right to stream content without any limitation on the creation of derivative works. 227

This conclusion is not, however, groundbreaking in application. Game companies regularly maintain the absolute right to use gameplay (e.g., in advertising) royalty free through the EULAs entered into by players. 228 Likewise, many EULAs provide the gamer with the ability to stream gameplay (royalty free) within the company's discretion. ${ }^{229} \mathrm{~A}$ company/player joint authorship determination (or lack thereof) is unlikely to change this contractually mandated situation (assuming enforceability of the EULA).

\section{B. Player/Player Joint Authorship}

The rise of streaming of esports further thrust two types of games to the fore: multiplayer online battle arena and first(or third)-person shooters. 230 Both variants are commonly featured in competitions between multiple teams in

225 See supra Section II.B. (discussing video game EULAs).

226 See supra note 214 and accompanying text (listing written agreements as a factor tending to establish the requisite intention).

227 Cf., e.g., Electronic Arts User Agreement, supra note 103 (contemplating player intellectual property without expressly restricting creation of derivative works). Regarding the creation of derivative copyrights see supra Section III.A.

228 See, e.g., Fortnite End User License Agreement, supra note 123 ("[Players] give [the game company] permission to ... create derivative works of [and otherwise use user generated content], in whole or in part, including for commercial publicity and marketing purposes, in any country.").

229 See, e.g., Fan Content Policy, supra note 109 (allowing players "to monetize web videos" but reserving an absolute right to revoke this permission).

230 Cf. Mariona Rosell Llorens, eSport Gaming: The Rise of a New Sports Practice, 11 SpORT, ETHICs \& PHIL. 464, 471-72 (2017) (observing the success of some games of these types). 
increasingly complex game situations.231 Free-for-all deathmatches (where every character is against every other character) have likewise risen in popularity. 232 These situations again present substantial joint authorship issues.

On this issue, gamers initially satisfy the requirement that they act to form an "inseparable" work233 having "little or no meaning standing alone."234 A multiplayer game recording becomes meaningless should one remove one or more players from the action (and audiovisual depictions thereof). 235 By their very nature, online multiplayer games are designed to facilitate competition between parties presented in an audiovisual form. The fact that the players are unlikely to consider copyright implications is unimportant; their

231 See id.; see also supra text accompanying notes 149-53 (discussing the complexity of modern games).

232 The popularity of "battle royale," winner-take-all games, like PlayerUnknown's Battlegrounds (PUBG) and Fortnite emerged in 2017 and continued through 2018, by which time more than 400 million accounts registered across different versions of PUBG. See Phil Hornshaw, The History of Battle Royale: From Mod to Worldwide Phenomenon, Digit. TRENDS (Apr. 10, 2019), https://www.digitaltrends.com/gaming/history-ofbattle-royale-games/ [https://perma.cc/CV3R-6APY]. Despite their recent popularity, however, battle royale games have existed in various forms for years. See id.

23317 U.S.C. $§ 101$ (2018).

234 See supra note 209 and accompanying text. Elaborating on inseparability, the Eastern District of Louisiana stated:

Parts of a unitary whole are considered "inseparable" when they have little or no meaning standing alone. For example, when two authors collaborate to produce one written text, their contributions are inseparable. Parts of a unitary whole are considered "interdependent" when "they have some meaning standing alone but achieve their primary significance because of their combined effect." The lyrics and music of a song are often such interdependent parts. The authors of a joint work are co-owners of the copyright in that work.

BTE v. Bonnecaze, 43 F. Supp. 2d 619, 622 (E.D. La. 1999) (citations omitted).

235 Put another way, a recorded multiplayer game would make little sense where one player's contribution did not appear in the recording. 
independent decisions regarding the audiovisual output embodied in each collective game strongly suggest that they acted with the requisite implied intent. 236

A related issue is whether each individual player contributes sufficient matter to be deemed an author of the work; a de minimis addition is likely insufficient for copyright to attach. 237 While the creativity necessary to exceed de minimis contribution is low, 238 some creative contribution is necessary. Furthermore, to satisfy the requirement that each party contribute copyrightable material (e.g., expression reduced to a tangible medium, which becomes part of an inseparable whole), we must evaluate at what point gameplay is actually reduced to a tangible medium.

\section{Recording in Server}

As discussed previously, there is some (but not uniform) case law finding that creation of a RAM copy of audiovisual gameplay on a server constitutes fixation. 239 If a court were to apply this line of cases, there is a high probability of joint authorship among players. In this instance, the server's RAM copy of the game embodies all of the gameplay within a given match. 240 The creative output of every player is fixed in temporary memory, which contributes to the inseparable whole of the entire game session. In this situation, each player is likely a joint author (potentially alongside the game company) of the aggregate whole of the session. Should individual players then isolate portions of this aggregate work for display (e.g. isolating their gameplay), they may be liable to other joint authors for use of a portion of the joint work. 241

236 See supra notes 212-14 and accompanying text (discussing the intent element).

237 See Words \& Data, Inc. v. GTE Commc'ns Servs., Inc., 765 F. Supp. 570, 575-76 (W.D. Mo. 1991).

238 See supra Section III.B.

239 See supra notes 180-83 and accompanying text.

240 Where a server is running the entire multiplayer game, it will necessarily have access to (and make copies of) the entire multiplayer game.

241 See Ashton-Tate Corp. v. Ross, 916 F.2d 516, 522-23 (9th Cir. 1990); Donovan v. Quade, 830 F. Supp. 2d 460, 495-96 (N.D. Ill. 2011). 


\section{Local Recording by the Video Game}

The case for joint authorship in an audiovisual gameplay where fixation occurs on an individual gamer's console is cognizable, if weaker. Initially, if the copy created on PlayerOne's computer solely includes the gameplay occurring in their immediate vicinity, the scope of potential co-authors is diminished. Players that never crossed PlayerOne's path added nothing of creativity to that particular copy of PlayerOne-centric gameplay, and thus, those parties would not surpass the requisite de minimis contribution.

A second concern regarding joint authorship and local recording pertains to control of the recording. ${ }^{242}$ To qualify as an author, one must "actually create[] the work, that is, the [author] translates an idea into a fixed, tangible expression."243 If an author is not responsible for the fixation of their expression, they are unlikely to be a joint author. ${ }^{244}$ This is premised upon the idea of authorship-as-fixation, whereby the party who reduces a work to a tangible medium is commonly recognized as the author. Justice Thurgood Marshall embodied this approach in recognizing that the author "is the party who actually creates the work, and "the person who translates an idea into a fixed, tangible expression [is] entitled to copyright protection." 245

Assuming that the gameplay's passing through server memory is insufficient to fix it in a tangible medium, 246 the individual gamer whose private console is recording the gameplay may be the sole author (or a joint author with the game company) as per authorship-as-fixation. The other gameplayers may, however, retain authorship if the private

242 See John Tehranian, Copyright's Male Gaze: Authorship and Inequality in a Panoptic World, 41 HARV. J.L. \& GENDER 343, 353-54 (2018) (discussing and criticizing authorship-as-fixation).

243 Cmty. for Creative Non-Violence v. Reid, 490 U.S. 730, 737 (1989).

244 See Two Palms Software, Inc. v. Worldwide Freight Mgmt. LLC., No. 10-cv-1045, 2012 WL 2419927, at *3 (E.D. Mo. June 26, 2012).

245 Cmty. for Creative Non-Violence, 490 U.S. at 737.

246 If the server memory fixes a copy of the gameplay, then any subsequent recordings are likely derivative works arising from the serverbased joint work. Cf. supra Section III.A. (discussing derivative works). 
copy is being made "by or under [their] authority." 247 This rule allows a party to be an author where another authorized entity engages in "rote or mechanical transcription that does not require intellectual modification or highly technical enhancement" 248 The question posed thus becomes whether a single gamer's recording of gameplay on their private console is "authorized" by other players. 249

To address whether other gamers authorized this copy, we look to analogies from the law of agency. In that realm, a person authorizes an action if they are aware of it, even if they did not specifically approve of it, so long as their acquiescence in it reasonably indicates approval.250 On this point, the Restatement of Agency has been cited for the proposition that a "principal's knowledge - actual and constructive - is the key to a finding of implied authority." 251 The touchstone of implied authorization to fix an expression is thus the putative authors' knowledge of the recording.

This requisite knowledge can be shown or implied through default game settings whereby all private consoles record a copy of the action. In such a situation, each party is creating their own private copy, which is likely to give them notice that others are doing the same by default. As an example, Fortnite automatically records and stores local copies of gameplay on each private console. ${ }^{252}$ In such a situation, each player who

247 See 17 U.S.C. $\S 101$ (2018) (stating the requirements for fixation).

248 See Andrien v. S. Ocean Cnty. Chamber of Com., 927 F.2d 132, 134 35 (3d Cir. 1991) (discussing the rule and collecting cases applying it).

249 It is notable that legal capacity to "authorize" another's recording of their gameplay may be influenced by the age of the player (e.g., if they are an adult). Further research may be warranted on this point.

250 See Esso Int'l, Inc. v. SS Captain John, 443 F.2d 1144, 1148 (5th Cir. 1971) ("Bright Star most assuredly acquiesced in, if it did not expressly approve, this course of conduct by Gissel \& Co. with Esso. Knowledge of, and acquiescence in, the agent's acts can be enough to establish implied authority if it manifests the principal's consent to the agent's acts. The test in this regard is whether the agent may reasonably draw an inference that the principal intended him so to act.").

251 Edwards v. Born, Inc., 22 V.I. 426, 430 (D.V.I. 1986) (citing Restatement (SECOND) OF Agency § 26 cmt. c (AM. L. Inst. 1958)).

252 See Fortnite Battle Royale - Replay System, supra note 195. 
makes more than a de minimis creative contribution to the private individual's specific recording is likely to be a joint author. That conclusion may somewhat be weakened where recording is not a default setting or where most parties can be shown to not be aware of the feature (such that they cannot impliedly authorize the recording).

\section{Local Recording Outside the Video Game}

The gamer's argument of joint authorship is likely at its nadir when recording is done by another player through some means outside of the game. When an individual player uses a third-party recording application-such as Twitch 253 - other gamers' ability to assert that they impliedly authorized the fixation is low. Recording gameplay (e.g., while streaming) is likely insufficient to put all other players on notice that fixation is occurring. And without knowledge of the recording, the other gamers cannot give the implied authorization needed for joint authorship.

The interplay of default in-game recording and simultaneous out-of-game recording complicates the issue. As discussed above, a default in-game recording favors a finding of wide-spread joint authorship, while external recording does not. Where both occur at the same time, a variety of arguments are implicated. Independent creation is a defense to a copyright infringement, so if the in-game and external copies are made independently, both copyrights can exist simultaneously. 254

253 See Video on Demand, supra note 200.

254 See Calhoun v. Lillenas Publ'g, 298 F.3d 1228, 1233 (11th Cir. 2002). Thus, the court analyzed two songs in the following way:

Given the limited number of musical notes (as opposed to words in a language), the combination of those notes and their phrasing, it is not surprising that a simple composition of a short length might well be susceptible to original creation by more than one composer. However, in the realm of copyright, identical expression does not necessarily constitute infringement. Just as two paintings of the same subject in nature may appear identical, the two paintings' origins may be of independent creation. 
In this instance, gamers may argue that the individual using a third-party application (e.g., Twitch) had access to their joint work (e.g., the in-game created copy), which would defeat assertions of independent creation. 255 This argument is, however, likely to fail under current case law. 256 While the third-party copy of the gameplay will be a near verbatim duplicate of the in-game copy, it was not derived from the ingame copy. Rather, both versions were derived from game output that was separately recorded. Restated, the video game produces an audiovisual output that is then recorded in parallel by both systems; there is no actual copying by the third-party recording application. Thus, despite similarities, joint authorship may exist in a game-created copy of gameplay, while sole authorship (or game company/individual) authorship may exist for the copy created by a third-party application.

In summary, players' arguments claiming joint authorship (i.e., authorship by multiple players and potentially the game company) are strongest if a court finds fixation of the audiovisual output within the server's temporary memory. In that instance, all players that make some contribution are likely authors, and any other game play recordings are likely derivative works thereof. While there is case law to support this conclusion, it is not uniform, and associated legal conclusions are not certain. Should courts find no fixation at the server, private in-game recordings are likely to create a joint authorship situation, while private third-party application recordings are more likely to be solo-authored (or authored by a single player with the game company).

Id. at 1232-33 (footnotes omitted).

255 See Selle v. Gibb, 741 F.2d 896, 901 (7th Cir. 1984) (suggesting that access is strong circumstantial evidence of copying).

256 See Erickson v. Blake, 839 F. Supp. 2d 1132, 1138 (D. Or. 2012) (stating that parties are free to use non-protected parts of a work without infringing). In this situation, the un-recorded game output is not protected by copyright law, and thus, can be used by any party. 


\section{IMPLICATIONS AND STRATEGIC RESPONSES}

The implications of gameplay copyright and potential joint authorship are significant. Copyright protection allows streamers to take action to protect their streams in much the same way that traditional sports leagues use copyright to protect their broadcasts. 257 This is not a panacea for celebrity streamers, however, as it affords some rights to players with whom the celebrities compete. Those competing players may be entitled to a share of the streamers' profits. 258 This presents substantial concerns for game companies who want to encourage player interaction without allowing their games to become the focal point of copyright accounting lawsuits. The following subsections discuss anticipated strategic behaviors from gamers and game companies.

\section{A. Preventing Copying of Streams}

The findings in this paper have value for individual gamers. Gameplay from streaming celebrities such as Dr DisRespect and Ninja is a valuable commodity. 259 This value will encourage free-riding by others who would like to make money off of the celebrity's reputation. Copyright provides mechanisms to preclude certain types of appropriation. 260

Many streaming celebrities annotate or embellish their gameplay through real time commentary. ${ }^{261}$ Assuming these individuals maintain the right to create derivative

257 Cf. supra notes 162-64 and accompanying text (discussing protection for traditional sports broadcasts).

258 See Craig Y. Allison, Note, Does a Copyright Coowner's Duty to Account Arise Under Federal Law?, 90 Mich. L. REV. 1998, 2000 (1992).

259 See Maria Törhönen et al., Fame and Fortune, or Just Fun? A Study on Why People Create Content on Video Platforms, 30 InTERnET RsCH. 165, 178-79 (2020).

260 See, e.g., 17 U.S.C. $§ 502$ (2018) (authorizing injunctions to restrain infringement).

261 See Taylor Clark, How to Get Rich Playing Video Games Online, NEW Yorker (Nov. 13, 2017),

https://www.newyorker.com/magazine/2017/11/20/how-to-get-rich-playingvideo-games-online [https://perma.cc/Q9VB-SDHB] (describing Twitch streamers interacting with their audiences). 
audiovisual works in their gameplay, 262 their rights in these embellishments are strong. ${ }^{263}$ Additions to pre-existing works can exhibit sufficient creativity to warrant copyright protection, 264 which in turn allows gamers to seek damages and injunctions for unauthorized copying. 265

Enterprising free riders may, however, attempt to circumvent these protections by stripping away streamers' embellishments. For example, one might remove the creative commentary from a work and then add new strategy discussions or general commentary. Case law recognizes that individuals can utilize any public domain elements of a work without penalty. 266 Thus, if the original streamer hopes to prevent this type of activity, they must establish rights in the underlying gameplay.

As discussed in Part III, we argue that modern gameplay presents the opportunity for a player to fix a sufficiently creative work in a digital medium to warrant copyright protection. 267 This is a derivative copyright, but assuming it was created pursuant any contractual limitations (e.g., EULAs), it provides the creator with the ability to seek legal redress. 268 Our research does, however, present some limitations on these rights by recognizing that audiovisual works of gameplay may have multiple authors to whom accountings may be owed.

262 For an overview of derivative works, see Section III.A.

263 Cf. Soptra Fabrics Corp. v. Stafford Knitting Mills, Inc., 490 F.2d 1092, 1094 (2d Cir. 1974) (holding that a slight alteration in a fabric design's appearance supported a derivative work copyright).

264 See Gibson Tex, Inc. v. Sears Roebuck \& Co., 11 F. Supp. 2d 439, 442 (S.D.N.Y. 1998) (discussing the creativity threshold).

265 See 17 U.S.C. $§ \S 502,504$ (2018).

266 See Erickson v. Blake, 839 F. Supp. 2d 1132, 1137-38 (D. Or. 2012). We do not address here whether the underlying audiovisual work is in the public domain; we note only that parties can use a work without a third party's permission if that third party has no rights in the work.

267 See supra Sections III.B-.C.

268 See supra note 127 and accompanying text. 


\section{B. Accounting to Other Gamers}

The primary thrust of our research evaluates authorship in audiovisual recordings of gameplay. Depending on methods of fixation and applicable court rulings, it is feasible that all gamers in a session could qualify as authors of a fixation of their game. This creates substantial legal and business issues, because while joint authors each maintain the right to use a copyrighted work in whatever manner they see fit, their coowners have the right to seek an accounting for associated profits. 269

As discussed in Section IV.B, if courts determine that fixation of the audiovisual output of a game occurs in the server's temporary memory, all players contributing a modicum of creativity will be a joint author. 270 Accordingly, we expect this to render most players authors, as per the discussion of creativity in Section IV.B.271 Application of this rule creates substantial new incentives in the video game replay/streaming industry.

Joint authors must distribute income according to state law principles, 272 which generally provide for proportional allocation among all owners. 273 To the extent that a single gameplay is created by ten or more gamer-authors, the potential income associated with a forced accounting from a random, non-celebrity streamer may be minimal. The costs underlying such an endeavor (e.g., attorney fees) are prohibitive given the small returns involved. Likewise, to the extent that a joint author lacks the ability to force video

269 See supra notes 215-17 and accompanying text.

270 See supra Section IV.B.1.

271 See supra Section IV.B.1.

272 See Membler.com LLC v. Barber, No. 12-CV-4941, 2013 WL 5348546, at *9 (E.D.N.Y. Sept. 23, 2013) (citing 17 U.S.C. § 201).

273 See, e.g., Levinson v. Levinson, No. CV WDQ-08-1974, 2009 WL 10727329, at *3 (D. Md. Mar. 24, 2009) (noting that Maryland law gives each author a "just share or proportion" (internal quotation marks omitted) (quoting Wathen v. Pearce, 3 A.2d 486, 490 (1939)). 
takedowns,274 nuisance value litigation is of minimal concern. 275

There are, however, increased incentives to seek an accounting from a celebrity streamer, given that "per-hour rates for endorsing a company during a live stream can reach as high as five figures for the most popular gamers." 276 Standing alone, this is unlikely to be a common event. 277 To seek such an accounting, an individual would have to play alongside or against a celebrity (rare) and be capable and willing to engage in a legal battle for a share of income (again, unlikely).

This does, however, incentivize collective action towards accounting. Opportunistic attorneys could facilitate multiplayer accountings to decrease per-gamer costs associated with underlying legal hurdles.278 The opportunity for an attorney to make a significant income would render this a significant possibility. Such a situation may pose a legitimate financial issue for celebrity streamers. In response, they will rationally take strategic action to avoid this problem.

Optimally, celebrities would obtain copyright waivers from other players before the game begins, but absent facilitation

274 See Mapp v. UMG Recs., Inc., 208 F. Supp. 3d 776, 789-92 (M.D. La. 2016), vacated in part on other grounds, No. 15-602, 2017 WL 3675419 (M.D. La. May 3, 2017) (observing that joint authors cannot make or grant exclusive use of their joint work).

275 See Michael J. Meurer, Controlling Opportunistic and AntiCompetitive Intellectual Property Litigation, 44 B.C. L. REv. 509, 525-28 (2003) (discussing the role of injunctions in nuisance litigation).

276 Patrick Shanley, How Top Gamers Earn up to $\$ 15,000$ an Hour, HollyWOOD REP. (June 3, 2019, 6:00 AM),

https://www.hollywoodreporter.com/news/top-gamers-earning-up-15000an-hour-1214953 [https://perma.cc/3GVD-J3E9].

277 Due to the fact that celebrities are uncommon by their very nature, the odds of any given game being played against a celebrity are relatively low.

278 See Mendez v. Reinforcing Ironworkers Union Loc. 416, No. 09-cv02332, 2013 WL 4506447, at *3 (D. Nev. Aug. 23, 2013) ("[T]he marginal cost of each additional plaintiff is considerably smaller than the cost of the first plaintiff. In nearly any case, many of the plaintiffs' activities and time spent on those activities would be mostly the same regardless of the number of plaintiffs involved."). 
by the game company, this is not feasible logistically. 279 Further, waivers from minors or parties outside the United States may be unenforceable. 280 We thus expect celebrities to respond through different strategic behaviors in creating their content and defending against accounting claims.

As discussed in Section IV.B.3, claims of joint authorship are at a minimum where initial game fixation occurs through a third-party (non-game) application.281 Accordingly, the rational celebrity streamer will minimize accounting concerns by utilizing available recording software outside of the game itself. This behavior does not, however, fully insulate their streaming income.

Where a court determines that fixation of gameplay occurs within server memory, gamer joint authorship claims are at their peak. 282 We can thus expect strategic litigation from celebrity streamers to avoid such a finding. Where a lawsuit for accounting is filed, potential repeat litigants (e.g., the celebrity streamer) will rationally seek to create positive precedent by litigating cases where a court shows a hesitance to find server memory game fixation. ${ }^{283} \mathrm{~A}$ finding of no server fixation undermines claims of gamer joint authorship, which benefits celebrity gamers. In contrast, these streamers will seek to settle claims when the facts are not in their favor and bad precedent could be established.284

279 We believe it unlikely that a game company would force parties to enter into a copyright waiver before every game they play. This opinion only extends to everyday gaming; waivers might be possible or even mandated in tournament esports. The enforceability of such waivers for minors warrants further research, though it is beyond the scope of this paper.

280 Cf., e.g., Kelly v. United States, No. 10-CV-172, 2014 WL 4793009, at *3-4 (E.D.N.C. Sept. 25, 2014) (stating that a minor's liability waiver is unenforceable but that a parent might be able to execute a waiver on behalf of a minor).

281 See supra Section IV.B.3.

282 See supra Section IV.B.1.

283 See Frank B. Cross, In Praise of Irrational Plaintiffs, 86 CoRnell L. REV. 1, 1 (2000) ("[R]epeat player litigants . . have a strong economic interest to engage in strategic precedent setting and reduce their potential liability in future cases.").

284 See id. at 8. 
While these individual-level concerns and behaviors are important for celebrity gamers, their financial issues are dwarfed by those associated with game companies. The next subsection discusses expected behaviors from these parties to avoid legal entanglements and brand harm.

\section{Considerations for Game Companies}

Game companies do not want their games to be the subject of copyright accounting lawsuits; it is bad for their brands. 285 This issue could be avoided by strictly enforcing their copyrights and demanding that streaming services (e.g., Twitch) do not broadcast their games. 286 But most companies do not want to stop the streaming that brings about these lawsuits, because it functions as free advertising. 287 Within these boundaries, additional contractual (i.e., EULA) limitations may be the only appealing resolution.

EULA restrictions are unfortunately not a simple, or perfect, strategic fix. The limitation must be broad enough to preclude assertion of joint authorship among gamers, in order to stop accounting lawsuits. The restrictions should not, however, defeat all claims of copyright in audiovisual gameplay. As discussed in Part III, streamers are afforded the ability to prevent verbatim copying of their content.288 If a game company adds EULA language to defeat copyright in all derivative works, streamers lose this protection, which could discourage their streaming activities. This would be strategically foolish for game companies, because it injures

285 See Kendall Salter, The Trouble with Tags: Seeking Mark Protection for Corporate Branded Hashtags-More Trouble than It's Worth?, 43 J. CORP. L. 699, 713 (2018) ("Corporations should avoid ... negative association with an all-important brand.").

286 See, e.g., Ball, supra note 13, at 259 ("In 2017, professional (and exceptionally controversial) streamer, Felix "PewDiePie" Kjellberg received a Digital Millennium Copyright Act (DMCA) takedown request from game publisher Campo Santo, ordering YouTube to delete any of Kjellberg's past and future streams featuring Campo Santo games.").

287 Cf. Clark, supra note 69 (interviewing streamers mentioning the free advertising idea).

288 See supra Part III. 
celebrity gamers' capacity to control their outputs while game companies simultaneously court these celebrities to play their games. 289

Lastly, there remains a concern associated with all EULAs: enforceability. To this end, legally binding assent must be secured from all players. This is not, however, a simple case of offer and acceptance. Agreement standards for joint authorship vary from country-to-country. 290 The ability to enter into a binding contract (e.g., a EULA) likewise varies across jurisdictions. 291 In a market that includes gamers from across the globe and of varying ages,292 EULAs must be tailored with care to meet their goals (e.g., avoiding joint authorship by gamers).

\section{CONCLUSION}

The rapid expansion of the esports industry and the emergence of streaming sites such as Twitch have created a fast-growing segment of the entertainment industry. ${ }^{293}$ With

289 See Janet Perez, Serious Gamers Listen Up! You Could Play Your Way to Big Bucks, Komando (May 26, 2019),

https://www.komando.com/technology/serious-gamers-listen-up-you-couldplay-your-way-to-big-bucks/568897/ [https://perma.cc/L7ZW-KKLL] ("Video game companies are courting professional gamers to promote their new livestream games.").

290 See Staff of S. Subcomm. on Pats., Trademarks \& Copyrights of THE S. COMm. ON THE Judiciary, 86Th Cong., JoInt Ownership OF Copyrights 90 (Comm. Print 1960) (George D. Cary, primary author).

291 René Demogue, The Impossibility of Effecting Contractual Incompetence and Its Consequences, 31 YALE L.J. 626, 626 (1922); cf. also Christina Lembo, Comment, FIFA Transfer Regulations and UEFA Player Eligibility Rules: Major Changes in European Football and the Negative Effect on Minors, 25 Emory Int'l L. Rev. 539, 573-75 (discussing differences among EU countries in the enforceability of minors' contracts).

292 Future research into the ability of minors to enter into game-related contracts and the impact thereof is warranted.

293 See John T. Holden, Anastasios Kaburakis \& Ryan Rodenberg, The Future Is Now: Esports Policy Considerations and Potential Litigation, 27 J. Legal Aspects Sport 46, 47 (2017). One company has projected the annual growth rate of video game live streaming to exceed 19 percent between 2019 and 2025. See Live Game Streaming Market to Grow at a CAGR of 19\% - Global Drivers, Restraints, Opportunities, Trends, and 
more than sixty percent of the American population engaging in some form of gaming by the end of the last decade, video games have become mainstream. ${ }^{294}$ With growing amounts of content consumed over user-generated streaming services, the existing jurisprudence is certain to be tested.295 The importance of the user-generated gameplay is such that the concerns we have identified here cannot be ignored. Both game companies and content producers should begin taking proactive steps to protect their content.296 However, there remains some exposure for content producers to provide an accounting to joint creators of their content. 297

We recommend that streamers and game companies be proactive in their attempts to stop the unauthorized use of content, and invest strategically in avoiding litigation, which could generate adverse precedent. Given the seemingly inevitable cascade of litigation that is destined to follow initial efforts to disrupt the status quo by potential joint authors, it is necessary for both streamers and game companies to work proactively to avoid initial efforts to litigate the substantive issues and to later minimize the harm of an adverse holding. As a result of our findings we suggest that streamers and

Forecast 2019-2025, BUs. WIRE (July 8, 2019, 8:24 AM), https://www.businesswire.com/news/home/20190708005399/en/Live-GameStreaming-Market-Grow-CAGR-19 [https://perma.cc/GXR4-Y3BL].

294 See John T. Holden, Ryan M. Rodenberg \& Anastasios Kaburakis, Esports Corruption: Gambling, Doping, and Global Governance, $32 \mathrm{MD}$. J. InT'L L. 236, 239 (2017); Ben Lindbergh, The Mainstream Media Is Not Playing Games, THE RINGER (Oct. 25, 2019, 7:20 AM), https://www.theringer.com/2019/10/25/20929604/the-mainstream-mediais-not-playing-games [https://perma.cc/G8V7-9LCL] (noting that esports and the video game industry have begun receiving increased attention in mainstream news outlets like The Washington Post).

295 See Sarah Perez, Twitch to Top 40 Million US Viewers Next Year, Forecast Says, TEchCRUNCH (Feb. 20, 2020, 11:58 AM), https://techcrunch.com/2020/02/20/twitch-to-top-40-million-u-s-viewersnext-year-forecast-says/ [https://perma.cc/36BW-9NVZ] (discussing yearover-year viewership numbers).

296 See supra Sections V.B-C.

297 See supra Section V.B. 
game companies act promptly to address deficiencies in their structures to avoid costly future consequences. 298

298 The full scope of potential methods to address these issues is beyond the scope of this paper and may merit future research. 